NASA/TM-2004-213222

NEXT Ion Engine 2000 Hour Wear Test Results

George C. Soulas, Hani Kamhawi, and Michael J. Patterson

Glenn Research Center, Cleveland, Ohio

Melissa A. Britton and Michael M. Frandina

QSS Group, Inc., Cleveland, Ohio 
Since its founding, NASA has been dedicated to the advancement of aeronautics and space science. The NASA Scientific and Technical Information (STI) Program Office plays a key part in helping NASA maintain this important role.

The NASA STI Program Office is operated by Langley Research Center, the Lead Center for NASA's scientific and technical information. The NASA STI Program Office provides access to the NASA STI Database, the largest collection of aeronautical and space science STI in the world. The Program Office is also NASA's institutional mechanism for disseminating the results of its research and development activities. These results are published by NASA in the NASA STI Report Series, which includes the following report types:

- $\quad$ TECHNICAL PUBLICATION. Reports of completed research or a major significant phase of research that present the results of NASA programs and include extensive data or theoretical analysis. Includes compilations of significant scientific and technical data and information deemed to be of continuing reference value. NASA's counterpart of peerreviewed formal professional papers but has less stringent limitations on manuscript length and extent of graphic presentations.

- TECHNICAL MEMORANDUM. Scientific and technical findings that are preliminary or of specialized interest, e.g., quick release reports, working papers, and bibliographies that contain minimal annotation. Does not contain extensive analysis.

- CONTRACTOR REPORT. Scientific and technical findings by NASA-sponsored contractors and grantees.
- CONFERENCE PUBLICATION. Collected papers from scientific and technical conferences, symposia, seminars, or other meetings sponsored or cosponsored by NASA.

- SPECIAL PUBLICATION. Scientific, technical, or historical information from NASA programs, projects, and missions, often concerned with subjects having substantial public interest.

- TECHNICAL TRANSLATION. Englishlanguage translations of foreign scientific and technical material pertinent to NASA's mission.

Specialized services that complement the STI Program Office's diverse offerings include creating custom thesauri, building customized databases, organizing and publishing research results ... even providing videos.

For more information about the NASA STI Program Office, see the following:

- Access the NASA STI Program Home Page at http://www.sti.nasa.gov

- E-mail your question via the Internet to help@sti.nasa.gov

- Fax your question to the NASA Access Help Desk at 301-621-0134

- Telephone the NASA Access Help Desk at 301-621-0390

- Write to:

NASA Access Help Desk

NASA Center for AeroSpace Information 7121 Standard Drive

Hanover, MD 21076 
NASA/TM-2004-213222

AIAA-2004-3791

NEXT Ion Engine 2000 Hour Wear Test Results

George C. Soulas, Hani Kamhawi, and Michael J. Patterson

Glenn Research Center, Cleveland, Ohio

Melissa A. Britton and Michael M. Frandina

QSS Group, Inc., Cleveland, Ohio

Prepared for the

40th Joint Propulsion Conference and Exhibit

cosponsored by the AIAA, ASME, SAE, and ASEE

Fort Lauderdale, Florida, July 11-14, 2004

National Aeronautics and

Space Administration

Glenn Research Center 


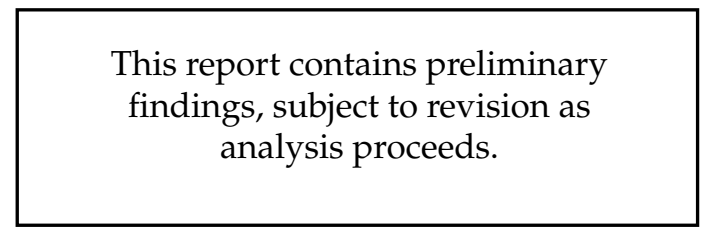

Available from

NASA Center for Aerospace Information 7121 Standard Drive

Hanover, MD 21076
National Technical Information Service 5285 Port Royal Road Springfield, VA 22100

Available electronically at http:/ /gltrs.grc.nasa.gov 


\title{
NEXT Ion Engine 2000 Hour Wear Test Results
}

\author{
George C. Soulas, Hani Kamhawi, and Michael J. Patterson \\ National Aeronautics and Space Administration \\ Glenn Research Center \\ Cleveland, Ohio 44135 \\ Melissa A. Britton and Michael M. Frandina \\ QSS Group, Inc. \\ Cleveland, Ohio 44135
}

\begin{abstract}
The results of the NEXT $2000 \mathrm{~h}$ wear test are presented. This test was conducted with a $40 \mathrm{~cm}$ engineering model ion engine, designated EM1, at a $3.52 \mathrm{~A}$ beam current and $1800 \mathrm{~V}$ beam power supply voltage. Performance tests, which were conducted over a throttling range of 1.1 to $6.9 \mathrm{~kW}$ throughout the wear test, demonstrated that EM1 satisfied all thruster performance requirements. The ion engine accumulated $2038 \mathrm{~h}$ of operation at a thruster input power of $6.9 \mathrm{~kW}$, processing $43 \mathrm{~kg}$ of xenon. Overall ion engine performance, which includes thrust, thruster input power, specific impulse, and thrust efficiency, was steady with no indications of performance degradation. The ion engine was also inspected following the test. This paper presents these findings.
\end{abstract}

\section{Introduction}

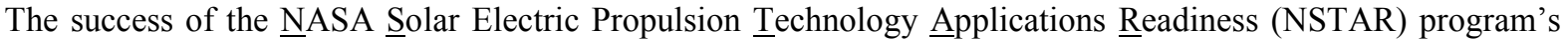
ion propulsion system on the Deep-Space 1 spacecraft has secured the future for ion propulsion technology for other NASA missions. ${ }^{1}$ While the $2.3 \mathrm{~kW}$ NSTAR ion engine input power and service life capabilities are appropriate for low power missions, in-space propulsion technology analyses conducted by NASA identified the need for a higher power, higher throughput capability $25 \mathrm{~kW}$ ion propulsion system targeted for robotic exploration of the outer planets. As a result, NASA's Office of Space Science awarded a research project to a NASA Glenn Research Center (GRC)-led team to develop the next generation ion propulsion system. ${ }^{2,3}$ The propulsion system, called NASA's Evolutionary Xenon Thruster (NEXT), consists of a $40 \mathrm{~cm}$ diameter ion engine, a lightweight, modular power processing unit with an efficiency and a specific power equal-to or better-than the NSTAR power processor, and a xenon feed system which uses proportional valves and thermal throttles to significantly reduce mass and volume relative to the NSTAR feed system.

Ion engine performance requirements include a specific impulse and thruster efficiency of at least 4050 and 0.67 , respectively, at full power. Based on NEXT Phase 1 design reference missions, the ion engine must provide a $270 \mathrm{~kg}$ propellant throughput capability at full power, which ultimately results in a $405 \mathrm{~kg}$ qualification throughput requirement.

The service life capability of the NEXT ion engine is being assessed by engine wear tests and modeling of critical engine components, such as the ion optics and cathodes. The first wear test of a NEXT ion engine was planned for a 2000 hour duration at a $6.9 \mathrm{~kW}$ input power. The highest thruster input power level was chosen because modeling has predicted that this power level will cause the severest engine erosion. The objectives of this early wear test included: characterizing thruster operation and performance over the duration of the test; identifying thruster life-limiting phenomena; and measuring critical thruster component wear rates.

This paper presents the results of the first NEXT wear test. A description of the test article is discussed in the next section. This is followed by a description of the test support hardware, which includes the power console, gas feed system, vacuum facility, and diagnostics. The test operating condition is then described. Finally, wear test and post-test inspection results are presented and discussed, and the service life of critical ion engine components assessed. 


\section{Test Article}

The wear test was conducted with an engineering model ion engine, designated EM1, which is shown in fig. 1. The engine utilizes a $40 \mathrm{~cm}$ beam extraction diameter, which is double the area of the NSTAR ion engine. The technical approach here is a continuation of the "derating" philosophy used for the NSTAR ion engine. Doubling the beam area allows operation at significantly higher thruster input power while maintaining low voltages and ion current densities. Thus, potential complications associated with high-voltage electrode operations are avoided, and engine longevity can be maintained.

The discharge chamber design of EM1 utilizes a hollow cathode electron emitter and a semi-conic chamber with a ring cusp magnetic circuit for electron containment created by high strength, rare earth magnets. A flakeretention scheme is employed in the discharge chamber, which also acts as a magnet retainer. The material, preparation, and installation processes employed for the flake-retention system are identical to those implemented on the NSTAR engine. ${ }^{4}$ The discharge chamber also incorporates a reverse-feed propellant injection process for the main plenum. Finally, EM1 utilizes new compact propellant isolators with a higher voltage isolation capability (about $1800 \mathrm{~V}$ ) than those used by the NSTAR engine.

The ion engine utilizes a neutralizer design that is mechanically similar to the Hollow Cathode Assembly of the International Space Station Plasma Contactor. ${ }^{5}$ Because the neutralizer cathode emission current range on the NEXT ion engine is similar to that of the Hollow Cathode Assembly, the NEXT neutralizer design can leverage off of the large cathode database already available with this design for risk reduction. ${ }^{6}$

The ion optics mounting assembly of EM1 is similar to that of the NSTAR ion engine, except that the diameter was increased to accommodate $40 \mathrm{~cm}$ beam extraction electrodes. The electrode geometry, referred to as ThickAccelerator-Grid (TAG) ion optics, is similar to that employed with the NSTAR engine except that the accelerator electrode thickness was increased to enhance engine service life. Initial performance results of this electrode geometry are described in detail in reference 7.

\section{Test Support Hardware}

\section{A. Power Console and Gas Feed System}

A power console similar to that described in reference 8 powered the ion engine. This power console utilized commercially available power supplies that allow for ion engine input powers of over $10 \mathrm{~kW}$ with beam power supply voltages of up to $2000 \mathrm{~V}$. A high purity gas feed system was used to provide xenon to the discharge cathode, main plenum, and neutralizer through separate mass flow controllers.

\section{B. Vacuum Facility}

The wear test was conducted in Vacuum Facility 6 at NASA GRC. This $7.6 \mathrm{~m}$ diameter $\times 22.9 \mathrm{~m}$ long facility is evacuated with 12 cryogenic pumps. For this test, the facility pressure was monitored by two ionization gages, with one located in the facility about $0.5 \mathrm{~m}$ radially below the ion engine and the second located on the cylindrical section of the facility wall about $3.2 \mathrm{~m}$ downstream of the ion engine. The facility base pressures were less than $1.3 \times 10^{-5} \mathrm{~Pa}$ $\left(1 \times 10^{-7}\right.$ Torr). Facility background pressures during wear testing are shown in Fig. 2 for both ionization gages. Increases in background pressures occurred at hours 1225, 1411, and 2029. At hours 1225 and 2029, the number of operational cryogenic pumps decreased to 11 and then 10, respectively. At hour 1411, one cryogenic pump failed while another was repaired; the number of operational cryogenic pumps did not change, but their distribution in the vacuum facility did change, causing the measured change in pressure. The facility pumping speed on xenon calculated with these ion gages with all cryogenic pumps operating was approximately $220,000 \mathrm{~L} / \mathrm{s}$ next to the ion engine and $360,000 \mathrm{~L} / \mathrm{s}$ at the facility walls.

Most of the facility's stainless steel interior surfaces downstream of the ion engine were lined with a flexible carbon material to reduce the amount of facility material that was back-sputtered onto the ion engine. The backsputtered mass rate was determined with a quartz crystal microbalance (QCM) located next to the ion engine, and was measured to be about $480 \mu \mathrm{gm} / \mathrm{cm}^{2} \cdot \mathrm{kh}$. Accurately determining the deposited thickness with the QCM alone was complicated by the presence of stainless steel constituents. The thickness of the back-sputtered deposition was, therefore, measured post-test to be $3.23 \mu \mathrm{m}$, yielding an average back-sputter rate of about $1.54 \mu \mathrm{m} / \mathrm{kh}$. 


\section{Diagnostics}

A computerized data acquisition and control system was used to monitor ion engine and facility operations and to control the power console. Data was sampled at a frequency range of $10-20 \mathrm{~Hz}$ and was stored once per minute. Ion engine currents and voltages were measured with current shunts and voltage dividers, respectively, and recorded. Facility pressures and individual mass flows to the ion engine were also sampled and recorded.

Ion beam diagnostics included circular planar probes mounted onto to a two-axis probe motion system for measuring beam plasma properties. There were a total of 9 planar probes with a $1 \mathrm{~cm}^{2}$ circular current-collecting area. The positioning system swept the probes in the radial and axial directions downstream of the engine ion optics, with $1.5 \mathrm{~m}$ travel in each axis. To measure beam current density profiles, the probes were biased negative with respect to beam plasma potential to repel electrons and are grounded through separate resistors that act as shunts to measure collected currents. To measure electron temperatures, number densities, and beam plasma potentials, the probe that swept through the geometric center of the ion optics was rewired to act as a Langmuir probe.

Erosion of critical ion engine components was monitored by three CCD cameras. One camera imaged the downstream neutralizer keeper and cathode orifice plate surfaces and was mounted to the ion beam diagnostics positioning system. The other two cameras imaged the downstream accelerator grid apertures and the discharge keeper and cathode orifice plates. These cameras were mounted to a separate two-stage positioning system that moved the cameras radially in front of the engine.

Finally, the engine was periodically connected to an electrically floating power supply circuit used to determine the screen grid transparency to discharge chamber ions and discharge keeper ion current. The circuit electrically tied the screen grid or the discharge keeper to the discharge cathode during normal operation, but biased the grid or keeper negative relative to discharge cathode potential to repel electrons and measure the collected ion current.

\section{Operating Condition and Performance Tests}

The NEXT ion engine is designed for solar electric propulsion applications, therefore, the ion engine was designed to throttle over a range of input powers. During the first phase of the NEXT program, during which this wear test was conducted, the throttling range was $1.1-6.9 \mathrm{~kW}$. The throttle table for this throttling range is shown in table 1. For the wear test, it was necessary to demonstrate the engine's propellant throughput capability at an operating point that causes the worst erosion and is the most stressful on engine operation. The highest engine input power, which corresponded to a $1800 \mathrm{~V}$ beam power supply voltage and $3.52 \mathrm{~A}$ beam current, met these criteria.

As shown in table 1, the wear test accelerator voltage was increased from $-250 \mathrm{~V}$ to $-210 \mathrm{~V}$ at the start of the wear test. Because there was a $74 \mathrm{~V}$ margin between the electron backstreaming limit and the $-250 \mathrm{~V}$ accelerator voltage), reducing this margin to about $34 \mathrm{~V}$ would reduce accelerator grid sputter erosion. This lower margin was chosen because it is similar to that of the NSTAR engine. ${ }^{9-11}$

Throughout the wear test, performance tests were conducted on the engine and engine components. Engine performance tests included measuring engine operating parameters and determining engine performance at several of the power levels indicated in table 1 .

Component performance assessments were periodically made on the discharge chamber, ion optics, and neutralizer. Ion optics performance included electron backstreaming, perveance, and screen grid ion transparency measurements. Discharge chamber performance was assessed by measuring discharge losses as a function of discharge propellant utilization efficiency at fixed discharge voltages. Neutralizer performance, which included keeper voltage measurements as a function of neutralizer flow, was also assessed.

\section{Results and Discussions}

The NEXT engine EM1 accumulated 2038 hours of operation at a thruster input power of $6.9 \mathrm{~kW}$ before being voluntarily shut down. At this full input power level, the NEXT engine processed about $43 \mathrm{~kg}$ of xenon, and provided a total impulse of $1.74 \times 10^{6} \mathrm{~N} \cdot \mathrm{s}$. The propellant throughput and total impulse demonstrated by the NEXT engine during this wear test was about $1 / 2$ and $2 / 3$ that demonstrated in the $8200 \mathrm{~h}$ NSTAR wear test engine, respectively. ${ }^{9}$

A total of four ion engine performance tests were conducted, covering operating points throughout the throttle table. There were a total of 36 test interruptions, which are listed in table 2 along with the interruption causes. No test interruption was caused by abnormal thruster operation. Following testing, the ion engine was removed and destructively examined. 


\section{A. Test Results}

\section{Engine Performance}

Engine performance parameters of value to mission planners include thrust, input power, specific impulse, and thrust efficiency. Calculated thrust, input power, specific impulse, and thrust efficiency as a function of time are plotted in figures 3, 4, 5, and 6, respectively, for operating points throughout the throttle table. For thrust calculations, the beam divergence thrust correction factor and the total doubly-to-singly-charged ion current ratio were assumed to be in the 0.976-0.977 and 0.034-0.044 ranges, respectively, based on reference 12. Ingested mass flow due to the facility background gas pressure was included in the total mass flow rate to the engine for determining specific impulse and thrust efficiency. ${ }^{13}$

The average calculated thrust, input power, specific impulse, and thrust efficiency at full power were $237 \mathrm{mN}$, $6.88 \mathrm{~kW}, 4110 \mathrm{~s}$, and 0.694 , respectively. Variations in all of these parameters were predominantly due to changes in beam current, which is maintained by adjusting the discharge current. On several occasions throughout the test, the beam current was inadvertently allowed to vary by as much as $+0.06 /-0.05$ A. So, for example, when the beam current decreased, the input power and thrust decreased, leading to decreases in specific impulse and thrust efficiency as well. Regardless, maximum variations in these full power values throughout the test were $+3 /-4 \mathrm{mN}$, $+0.10 /-0.13 \mathrm{~kW},+50 /-60 \mathrm{~s}$, and $+0.008 /-0.009$, respectively. Throughout the wear test, EM1 satisfied all thruster performance requirements.

Ion engine performance tests, which included operating points throughout the throttle table, were conducted four times during the wear test. During these short performance tests, the beam current was controlled within a tighter bandwidth. This ultimately resulted in performance values exhibiting significantly lower variability. Calculated thrust, thruster input power, specific impulse, and thrust efficiency for these tests ranged within only $0.5 \mathrm{mN}, 0.02 \mathrm{~kW}, 20 \mathrm{~s}$, and 0.003 , respectively, of their nominal values throughout the test.

\section{Discharge Chamber}

Discharge current and voltage as a function of time at full power are shown in figure 7. Average discharge currents and voltages were $19.5 \mathrm{~A}$ and $23.6 \mathrm{~V}$, respectively. Variations with time were generally within $\pm 3 \%$ of the average values. The figure also shows discharge current and voltage "spikes", which correspond to engine restarts. These "spikes" also account for most of the variations in the parameters.

The only notable trend, while small, was the discharge current required to maintain the beam current, which rose from a nominal start value of about 19.1 A to about 19.6 A by hour 140. As a result, discharge losses at full power, shown in figure 8 , increased from $127 \mathrm{~W} / \mathrm{A}$ to about $130 \mathrm{~W} / \mathrm{A}$ by hour 140 . Discharge losses at full power generally remained within 130 and $132 \mathrm{~W} / \mathrm{A}$ for the remainder of the test.

This initial $3 \mathrm{~W} / \mathrm{A}$ increase (i.e. a $2 \%$ increase) in discharge losses at full power is considerably smaller than that exhibited by the NSTAR engine. In three separate wear tests, NSTAR engine discharge losses increased by $10-15$ W/A within the first 500 hours of wear testing. ${ }^{9-11}$ That the initial change in the NEXT discharge losses was so small contributes to a more constant thruster input power, and, therefore, a more constant thrust efficiency at beginning of life for the NEXT engine.

Throughout the throttle table, discharge losses exhibited beginning-of-life trends that were a function of beam current. While discharge losses generally increased during the first 700 hours of the wear test at beam currents of 3.52 A and 2.70 A, discharge losses decreased during this time for beam currents of 2.00 A and 1.20 A. Regardless, all changes were $\leq 6 \mathrm{~W} / \mathrm{A}$ and there were no indications of significant, long-term performance degradation.

Figure 9 shows discharge losses as a function of discharge propellant utilization efficiency throughout the wear test for the highest and lowest beam currents of 3.52 A and 1.20 A, respectively. At each beam current, the ratio of main to discharge cathode flow rate was adjusted to maintain the nominal discharge voltage. Ingested mass flow due to the facility background gas pressure was included in the calculation of discharge propellant utilization efficiency. Data were obtained for a beam power supply voltages of $1180 \mathrm{~V}$ and $1800 \mathrm{~V}$ for the $1.20 \mathrm{~A}$ and $3.52 \mathrm{~A}$ beam currents, respectively. The figure shows that there were no significant changes in the functional dependence of discharge losses on propellant utilization efficiency at either beam current throughout the wear test.

Figure 10 shows discharge keeper voltage (i.e. keeper potential relative to discharge cathode potential) and ion current as a function of time at full power throughout the wear test. These parameters are significant because they impact the discharge keeper wear rate. The keeper voltage started at about $4.1 \mathrm{~V}$ and increased to about $4.4-4.5 \mathrm{~V}$ by hour 1200, where it remained for the rest of the test. The keeper ion current was steady at about $210 \mathrm{~mA}$ throughout the test. There were no significant changes in discharge keeper voltage and current throughout the wear test, indicating that the discharge keeper wear rate at full power was likely constant throughout the wear test. 


\section{Neutralizer}

Neutralizer keeper voltage as a function of time is plotted on figure 11 at full power. The keeper voltage operated at a mean value of about $10.6 \mathrm{~V}$ during the first $400 \mathrm{~h}$, then increased to about $10.8 \mathrm{~V}$ by hour 1050 . It remained at this level to the end of the wear test. The neutralizer keeper voltage exhibited voltage "spikes", as shown in figure 11. These voltage "spikes" correspond to engine restarts, which is similar to NSTAR neutralizer behavior. ${ }^{9-11}$

Coupling voltage, which is a measure of neutralizer cathode potential relative to vacuum facility ground, is plotted in figure 12 as a function of time at full power. The mean coupling voltage was steady at about $10.0 \mathrm{~V}$ $+0.3 /-0.5 \mathrm{~V}$. The low coupling voltage magnitude was due to the high keeper current and neutralizer flow rate. These high values were selected to ensure neutralizer operation in spot mode throughout ion engine service life while imposing only modest sacrifices in engine performance.

Both the neutralizer keeper and coupling voltages indicated no neutralizer performance degradation.

Figure 13 shows neutralizer flow at the onset of plume mode as a function of time for no beam extraction and at a 1.20 A beam current. Plume mode, which is defined here as a peak-to-peak neutralizer keeper voltage oscillation of greater than $\pm 5 \mathrm{~V}$, could not be identified at higher beam currents due to beam power supply instabilities. Data were measured at a beam power supply voltage of $1800 \mathrm{~V}$. As the figure indicates, plume mode varied within a $0.5 \mathrm{sccm}$ bandwidth throughout the wear test. There was at least a $1.4 \mathrm{sccm}$ flow margin between the plume mode and the nominal flow set point. This margin is considerably greater than that of the NSTAR ion engine, whose margin was less than or equal to $0.5 \mathrm{sccm}$ throughout the lower power levels of the NSTAR throttle table. ${ }^{9}$

\section{Ion Optics}

Accelerator currents as a function of time throughout the throttle table are plotted on figure 14. The "spikes" in the accelerator current at full power correlate with engine recycles, which is described in detail in reference 14 . The mean accelerator current at full power was $12.6 \mathrm{~mA}$. The decrease in accelerator current at full power at hour 1050 was related to a facility shutdown and the accelerator current increases at hours 1225 and 2029 were due to operation with 11 and then 10 cryogenic pumps, respectively.

Beginning-of-life accelerator currents for beam currents of 1.20-2.70 A at an $1800 \mathrm{~V}$ beam power supply voltage decreased by about $0.3 \mathrm{~mA}$ between the first two performance tests. The cause of the initial accelerator current decreases at these operating points was likely sputter erosion of the accelerator apertures at large ion optics' radii, which will be discussed later. The end-of-test accelerator currents were generally higher at beam currents above $2.00 \mathrm{~A}$ due to the reduced facility pumping speed. The remaining accelerator currents have been relatively constant.

NSTAR ion engine accelerator currents have not been as steady as NEXT accelerator currents. NSTAR engine accelerator currents generally started higher-than-nominal, and required up to 1500 hours to decrease to nominal values. ${ }^{9-10}$ The cause for this difference in behavior is presently unknown.

Total engine recycles and recycle rate as a function of time are plotted in figure15. The recycle rate during the first 84 hours of the wear test was high, with an average of 11.6 recycles per hour. The recycle rate gradually decreased between hours 84 and 300. The average recycle rate from hour 300 to the end of the test was typically less than 2.5 per hour. In comparison, a NSTAR wear test exhibited the same change in recycle rate with time. ${ }^{11}$ During that $1000 \mathrm{~h}$ wear test, the recycle rate started at about 9 per hour and steadily decreased with time. ${ }^{11}$ The NSTAR 8200 hour wear test operated with an average recycle rate of 1-2 per hour. ${ }^{9}$ The slightly higher average recycle rate for the NEXT engine is expected because the NEXT engine's beam extraction area and inter-grid electric field are $2 \mathrm{X}$ and $1.5 \mathrm{X}$ that of the NSTAR engine, respectively.

Perveance limits, electron backstreaming limits, and screen grid ion transparencies throughout the wear test are plotted in figures 16, 17, and 18, respectively. Perveance limits were determined from plots of accelerator current as a function of total voltage where the slope was $-0.02 \mathrm{~mA} / \mathrm{V}$ (i.e. the NSTAR criterion). Here, the total voltage is defined as the sum of the beam power supply voltage and the absolute value of the accelerator voltage. Electron backstreaming limits were determined by lowering the magnitude of the accelerator grid voltage until the indicated beam current increased by $1 \mathrm{~mA}$ due to backstreaming electrons. Screen grid ion transparencies were calculated as described in reference 15 .

Throughout the throttle table, perveance limits decreased during the wear test by $50-70 \mathrm{~V}$. The cause for this small perveance improvement was likely from accelerator grid aperture enlargement due to sputter erosion, which will be discussed in a later section.

End-of-test electron backstreaming limits were within $\pm 3 \mathrm{~V}$ of pretest values. However, electron backstreaming limit magnitudes typically decreased by as much as $7 \mathrm{~V}$ initially, and then increased to their end-of-test values. Screen grid ion transparencies followed a similar trend. End-of-test transparencies were within $+0.005 /-0.01$ of 
pretest values. However, these transparencies typically decreased by as much as 0.01 initially, and then either remained unchanged or increased to their end-of-test values. Although the magnitudes of the changes were generally small, the cause for these trends in electron backstreaming limits and screen grid ion transparencies is presently unknown.

Regardless, all changes in perveance limits, electron backstreaming limits, and screen grid ion transparencies were not significant enough to degrade ion optics' performance. Furthermore, all NEXT ion optics performance changes were less than or equal to those exhibited by the NSTAR ion optics during the first $2000 \mathrm{~h}$ of the $8200 \mathrm{~h}$ wear test. ${ }^{9}$

\section{Radial Beam Current Density Profiles}

Radial beam current density profiles were measured as close as $45 \mathrm{~mm}$ downstream from the geometric center of the ion optics. Regarding beam current density measurements, no attempt was made to repel charge-exchange ions from the probe or to account for secondary electron emission due to ion bombardment. Integration of the radial beam current density profiles (assuming azimuthal symmetry) yielded beam currents that were higher than the measured beam current by as much as $8 \%$. Possible sources of error are discussed in reference 15 .

Post-test radial beam current density profiles are plotted in figure 19 at $45 \mathrm{~mm}$ downstream of the ion optics. Beam current density profiles did not change significantly during the wear test. Variations in peak beam current density as a function of time at full power are shown in figure 20. Peak beam current densities at this axial location have been $3.97 \mathrm{~mA} / \mathrm{cm}^{2}+0.11 /-0.04 \mathrm{~mA} / \mathrm{cm}^{2}$. The resulting ion engine beam flatness parameter (i.e. the ratio of average-to-peak ion current density) ranged from 0.69-0.71 throughout the wear test at full power.

Other beam plasma measurements, as well as in situ erosion measurements, have been made during the wear test. These are discussed in greater detail in a companion paper. ${ }^{16}$

\section{B. Ion Engine Inspection Results}

Following the wear test, the ion engine was inspected and photographed in situ. The engine was then removed from the vacuum facility, disassembled, and destructively inspected. The following sections present and discuss the inspection results for the discharge chamber, discharge cathode, neutralizer, and ion optics assemblies.

\section{Discharge Chamber}

Other than some discoloration, the NEXT discharge chamber appeared to be in excellent condition. The interior flake containment mesh exhibited no spalling of sputter-deposited films. Debris was found on the bottom of the discharge chamber interior that appeared to be spalled material. Analysis of some of the debris showed that it was primarily composed of grid material. Furthermore, the shape and size of the debris suggested that it had spalled from the accelerator grid aperture walls. This debris will be discussed in a later section.

A two-dimensional mapping of the discharge chamber magnetic field was done both pre- and post-test. Comparison of these measurements indicated no change in magnetic fields within the measurement uncertainty. The operating temperature of the magnet rings at full thruster power was, therefore, low enough to prevent thermal degradation of the magnets.

\section{Discharge Cathode Assembly}

The discharge cathode assembly includes the cathode, heater, and enclosed keeper as major sub-assemblies. A visual inspection of the assembly showed the entire assembly to be in good condition, with the only external evidence of erosion being the downstream keeper and exposed cathode orifice plates.

Post-test cathode and keeper orifice diameters decreased, but only by $3.0 \%$ and $0.5 \%$, respectively, of their pretest diameters. The small cathode orifice diameter decrease was due to net deposition of keeper and cathode insert impregnate material. A similar decrease in cathode orifice diameter was noted for the NSTAR $8200 \mathrm{~h}$ wear test discharge cathode orifice, but no keeper material was noted there. ${ }^{9}$ That keeper material was found in the NEXT discharge cathode orifice was not surprising given its larger orifice diameter and, therefore, better line-of-sight to eroded keeper surfaces. The small keeper orifice diameter decrease was due to net deposition of sputtered keeper and cathode orifice plate material, and trace amounts of cathode insert impregnate material. The presence of cathode insert impregnate material downstream of the insert has been noted in past tests, and was, therefore, expected. ${ }^{9}$ This is also true of cathode orifice plate material on the keeper. ${ }^{9}$ The only difference was that this deposition was found in the keeper orifice, where the $8200 \mathrm{~h} \mathrm{NSTAR}$ wear test measured net erosion of this orifice.

The exposed, downstream cathode orifice plate and chamfer were visibly textured due to sputter-erosion. The cathode orifice plate was cross-sectioned and the thickness measured as a function of radius. There was no measurable thickness reduction of the cathode orifice plate. 
The cathode insert was also sectioned and inspected. The inspection revealed no anomalous material formations that would be indicative of life-limiting reactions due to exposure to reactive contaminants.

The keeper, whose primary function is to protect the discharge cathode from excessive sputter erosion, was sputter-eroded over the entire downstream surface and part of the orifice channel. The keeper was cross-sectioned and the thickness measured as a function of radius. The results are shown in figure 21 . The profile of the erosion pattern, including the sputter-eroded orifice chamfer, is qualitatively similar to that of the NSTAR $8200 \mathrm{~h}$ wear test engine. ${ }^{9}$ For the NEXT ion engine, the deepest erosion occurred at a radius of about $40 \%$ of the total keeper radius. At that point, a peak of about $15.3 \%$ of the keeper thickness had been eroded.

Assuming eroded depth is linear with time, erosion through the thickness of the keeper would be expected to occur at $13.3 \mathrm{kh}$ at full power, or after processing $281 \mathrm{~kg}$ of xenon. While wear-through of the keeper orifice plate occurs prior to the $405 \mathrm{~kg}$ propellant throughput requirement, keeper wear-through is not a thruster failure mechanism. Indeed, during a long duration NSTAR life test, the discharge keeper wore through its thickness and was eventually sputter-eroded away, but the thruster still operated successfully until the life test was voluntarily terminated.

Regardless, the NEXT program is addressing this possible issue by changing the keeper orifice plate and tube material to a carbon-based material whose sputter yield is significantly lower. Assuming eroded depth is linear with time, erosion through the thickness of a carbon-based keeper material would be expected to occur at about $86.8 \mathrm{kh}$ at full power, or after processing $1840 \mathrm{~kg}$ of xenon, which exceeds the $405 \mathrm{~kg}$ propellant throughput requirement.

\section{Neutralizer}

A visual inspection of the assembly showed the entire assembly to be in good condition, with the only external evidence of erosion being the downstream, exposed cathode orifice plate and a portion of the keeper tube exposed to the beam plume. The downstream keeper orifice plate was also discolored, as was the exposed keeper-to-ground insulator.

The post-test cathode orifice diameter showed no change, however, the keeper orifice diameter decreased, but only by $1.1 \%$ of the pretest diameter. The small keeper orifice diameter decrease was due to net deposition of sputtered facility and cathode orifice plate material.

The exposed, downstream cathode orifice plate and chamfer were visibly textured due to sputter-erosion. The cathode orifice plate was cross-sectioned and the thickness measured as a function of radius. No measurable thickness reduction was found. The cathode insert was also sectioned and inspected. The inspection revealed no anomalous material formations that would be indicative of life-limiting reactions due to exposure to reactive contaminants.

The keeper orifice plate discoloration was found to be composed of sputtered facility material. The upstream keeper plate also had trace amounts of cathode orifice plate material. The keeper orifice plate was cross-sectioned and the thickness measured as a function of radius. No measurable thickness reduction was found.

The downstream portion of the keeper tube that was exposed to the ion beam was sectioned and its thickness measured. The results are shown in figure 22. The worst-case erosion occurred less than $1 \mathrm{~mm}$ from the keeper orifice plate and eroded through $11.0 \%$ of the keeper thickness. Assuming eroded depth is linear with time, erosion through the thickness of the keeper tube would be expected to occur at $18.5 \mathrm{kh}$ at full power, or after processing $392 \mathrm{~kg}$ of xenon. While wear-through of the keeper tube would be expected to occur just prior to the $405 \mathrm{~kg}$ propellant throughput requirement, keeper tube wear-through is not a thruster failure mechanism. This is because an enclosed neutralizer keeper is not required for proper neutralizer operation.

Regardless, the NEXT program is addressing this possible issue by increasing the thickness of the keeper tube by $50 \%$. Assuming eroded depth is linear with time, erosion through the thickness of the thicker keeper tube would be expected to occur at about $27.8 \mathrm{kh}$ at full power, or after processing $587 \mathrm{~kg}$ of xenon, which exceeds the $405 \mathrm{~kg}$ propellant throughput requirement.

\section{Ion Optics}

Comparisons of pre- and post-test test alignment measurements showed that the screen and accelerator grid alignment had not changed during the wear test.

Pre- and post-test aperture diameter measurements using pin gages are shown in figures 23 and 24 for the accelerator and screen grids, respectively. Pretest diameters for the accelerator grid were $+11.1 \% /-15.6 \%$ of the nominal design point, while those of the screen grid were $+0 \% /-4.0 \%$ of the nominal design point. The larger variability in the accelerator grid aperture diameters was due to manufacturing difficulties associated with the thicker electrode. Recent NEXT ion optics manufacturing has focused on improving accelerator aperture tolerances. Aerojet, who is tasked with building a higher fidelity NEXT ion engine, has recently manufactured an accelerator 
electrode whose aperture tolerances are $+0.0 /-7.0 \%$ of the nominal design point, which is a significant improvement over the pretest tolerances of EM1. ${ }^{17}$

Comparisons of pre- and post-test aperture diameter measurements are shown in figures 23 and 24. Post-test screen grid aperture diameters were predominantly unchanged. Accelerator grid aperture diameter changes were small and generally increased with increasing radius. Within a radius of $15.3 \mathrm{~cm}$, accelerator apertures increased $\leq 4.4 \%$ of the nominal diameter, and were unchanged at the optics' center. This is not too surprising, given that pretest accelerator apertures were largest at the center and decreased radially outward. The increased aperture diameters were the likely cause of the improved perveance limits, shown in figure 16.

Beyond a radius of about $15.3 \mathrm{~cm}$, accelerator apertures exhibited an off-center, hexagonal star-shaped erosion pattern. Sample photomicrographs are shown in figure 25. The eroded points of the stars were chamfered through the electrode thickness and the extent of the erosion pattern generally increased with increasing ion optics' radius. This erosion likely occurred within the first $650 \mathrm{~h}$ of testing. This is because the accelerator currents for the $1.20-2.70 \mathrm{~A}$ cases at a $1800 \mathrm{~V}$ beam power supply voltage in figure 14 decreased by about $0.3 \mathrm{~mA}$ between the first and second performance tests. It is these operating points where over-focusing would be expected to be most severe because the discharge chamber plasma densities are at their lowest and total voltage at its highest.

This erosion pattern was found to be the result of three causes:

1. over-focused beamlet ions in this low plasma density region impinging upon the accelerator grid;

2. significantly smaller-than-nominal accelerator aperture diameters in this region; and

3. misaligned screen and accelerator apertures due to an under-compensated hole pattern.

The concern regarding this erosion is not structural failure of the accelerator grid, but an unclearable grid electrical short from spalled sputter material from this erosion. Figure 26 illustrates this concern. During the wear test, sputtereroded material from the hexagonal star-shaped pattern was deposited onto other accelerator aperture wall surfaces that did not experience significant sputter erosion. This material spalled off, likely when the thruster was exposed to atmosphere after the wear test. The discharge chamber debris discussed earlier had similar shapes and sizes as that shown in figure 26 , and, therefore, originated from these accelerator apertures walls. This debris was large enough to electrically short the grid gap.

The NEXT program is resolving this issue through several approaches conducted in parallel. First, grid clearing tests are being conducted at JPL to determine the largest size debris that the NEXT power processor can clear. With regard to the ion optics, the compensation of the hole pattern was modified to properly align the screen and accelerator apertures throughout the beam extraction area. Furthermore, as discussed previously, accelerator grid manufacturing improvements have reduced accelerator aperture diameter tolerances, especially at larger radii. Both modifications to the ion optics will reduce the generated amount of sputtered material. Finally, analyses and tests are in progress to determine what changes to the ion optics aperture geometries beyond a $15.3 \mathrm{~cm}$ radius are required, if any, to mitigate direct ion impingement from over-focusing.

Downstream accelerator grid erosion was quantified to determine accelerator grid service life capability with regards to pit and groove erosion. Figure 27 shows a sample pit and groove erosion pattern. Post-test pit and groove erosion patterns surrounding an aperture were mapped with a laser profilometer at three ion optics' radial locations: center, $5 \mathrm{~cm}$ radius (i.e. $1 / 4$-radius), and $10 \mathrm{~cm}$ radius (i.e. mid-radius). Little pit and groove erosion was seen beyond a $16 \mathrm{~cm}$ radius. The maximum depths of the six pits and grooves surrounding an accelerator aperture at each location were measured and are plotted in figures 28 and 29, respectively. While the pits surrounding the center aperture exhibited the deepest erosion, the grooves surrounding the 1/4-radius aperture exhibited the deepest groove erosion.

Assuming eroded depth is linear with time, pit erosion through the thickness of the accelerator grid would be expected to occur at $17.3 \mathrm{kh}$ at full power, or after processing $365 \mathrm{~kg}$ of xenon. However, pit erosion through the grid does not cause a thruster failure. Groove erosion through the grid thickness can lead to thruster failure due to accelerator grid structural failure. Groove erosion through the thickness of the accelerator grid would be expected to occur at $35.5 \mathrm{kh}$ at full power, or after processing $750 \mathrm{~kg}$ of xenon. This exceeds the NEXT service life requirement of $405 \mathrm{~kg}$ of xenon.

The upstream screen grid showed no signs of excessive erosion. To confirm this, the upstream side of a screen grid aperture located at mid-radius was mapped with a laser profilometer. Results showed insignificant wear around the screen aperture. Further evidence of insignificant screen grid erosion was the change in screen grid mass from the wear test. The screen grid gained 1.27 gm of mass, likely due to the deposition of accelerator grid material from erosion of the accelerator apertures. The accelerator grid lost $14.37 \mathrm{gm}$ of mass during the wear test due to aperture and downstream pit and groove erosion. 


\section{Ion Engine Service Life Assessment}

To determine the NEXT ion engine service life, service life assessments were conducted on critical NEXT ion engine components that included discharge chamber flake retention capability, both cathode inserts, both cathodes and keepers, and the ion optics. Wear test results were used, in part, to assess the service life capability of these components. The results of these assessments are listed in table 3 . Table 3 includes planned discharge cathode keeper, neutralizer keeper tube, and ion optics erosion modifications to the ion engine to improve engine service life. Furthermore, conservative failure criteria, such as erosion through the discharge keeper orifice plate and neutralizer keeper tube, were used. As the table shows, the NEXT ion engine will exceed its required propellant throughput capability of $405 \mathrm{~kg}$ associated with the NEXT Phase 1 design reference missions.

\section{Conclusions}

The results of the NEXT $2000 \mathrm{~h}$ wear test were presented. The wear test was conducted with a $40 \mathrm{~cm}$, engineering model NEXT ion engine designated EM1. At a full input power of $6.9 \mathrm{~kW}$, the NEXT engine accumulated $2038 \mathrm{~h}$ of operation, processed about $43 \mathrm{~kg}$ of xenon, and demonstrated a total impulse of $1.74 \times 10^{6} \mathrm{~N} \cdot \mathrm{s}$. The propellant throughput and total impulse demonstrated by the NEXT engine during this wear test were about $1 / 2$ and $2 / 3$ that of the $8200 \mathrm{~h}$ NSTAR wear test engine, respectively.

Overall ion engine performance, which includes thrust, input power, specific impulse, and thrust efficiency, were steady throughout the wear test with no indication of performance degradations. Throughout the duration of the test, EM1 satisfied all thruster performance requirements.

Discharge chamber, neutralizer, and ion optics operation during the wear test were evaluated. Discharge loss changes were $\leq 6 \mathrm{~W} / \mathrm{A}$ throughout the throttle table and there were no indications of long-term performance degradation. Neutralizer keeper and coupling voltages were typically steady, with no indication of performance degradation. Ion optics perveance limits improved by 50-70 V due to accelerator aperture enlargement. Pre-and post-test electron backstreaming limits and screen grid ion transparencies were with $3 \mathrm{~V}$ and 0.01 , respectively.

A post-test inspection was completed on EM1. The discharge chamber was in excellent condition with no spalling of the flake-containment mesh and no change in the magnetic fields. The discharge cathode assembly and neutralizer were also in good condition. The discharge keeper orifice plate was sputter-eroded over the entire downstream surface and part of the orifice channel, qualitatively similar to that observed with the NSTAR $8200 \mathrm{~h}$ wear test engine. Erosion through the thickness of the discharge keeper plate would be expected to occur after processing $281 \mathrm{~kg}$ of xenon. The downstream portion of the neutralizer keeper tube that was exposed to the ion beam was also sputter-eroded. Erosion through the thickness of the neutralizer keeper tube would be expected to occur after processing $391 \mathrm{~kg}$ of xenon. The NEXT program is addressing these possible issues by changing to a carbon-based discharge keeper material to reduce erosion rates and by thickening the neutralizer keeper tube by $50 \%$.

Comparison of pre- and post-test accelerator and screen grid aperture diameter measurements showed little change throughout most of the beam extraction area. Beyond a radius of about $15.3 \mathrm{~cm}$, however, accelerator apertures exhibited an off-center, hexagonal star-shaped erosion pattern. This erosion pattern was found to be the result of three causes:

1. over-focused beamlet ions in this low plasma density region impinging upon the accelerator grid;

2. significantly smaller-than-nominal accelerator aperture diameters in this region; and

3. misaligned screen and accelerator apertures due to an under-compensated hole pattern.

The concern regarding this erosion is creation of an unclearable grid electrical short from spalled sputter material from this erosion. The NEXT program is resolving this issue by resolving all the aforementioned causes. Downstream accelerator grid erosion was quantified to determine accelerator grid service life capability. Groove erosion through the thickness of the accelerator grid would be expected to occur after processing $750 \mathrm{~kg}$ of xenon, exceeding the NEXT service life requirement of $405 \mathrm{~kg}$ of xenon. The upstream screen grid showed no signs of excessive erosion.

To determine the NEXT ion engine service life, service life assessments were conducted on critical NEXT ion engine components. Wear test results were used, in part, to assess the service life capability of these components. It was determined that the NEXT ion engine will exceed its required propellant throughput capability of $405 \mathrm{~kg}$ with the planned modifications to the discharge keeper, neutralizer keeper, and ion optics to enhance component service life. 


\section{References}

${ }^{1}$ Polk, J.E., et al., "In-Flight Performance of the NSTAR Ion Propulsion System on the Deep Space One Mission,” IEEE Aerospace Conference Paper 8.0304, March 2000.

${ }^{2}$ Patterson, M.J., et al., "NEXT: NASA's Evolutionary Xenon Thruster Development Status," AIAA Paper 2003-4862, July 2003.

${ }^{3}$ Patterson, M.J., et al., "NEXT: NASA's Evolutionary Xenon Thruster," AIAA Paper 2002-3832, July 2002.

${ }^{4}$ Christensen, J.A., et al., "Design and Fabrication of a Flight Model $2.3 \mathrm{~kW}$ Ion Thruster for the Deep Space 1 Mission,” AIAA Paper 98-3327, July 1998.

${ }^{5}$ Patterson, M.J., et al., "Space Station Cathode Design, Performance, and Operating Specifications," IEPC Paper 97-170, August 1997.

${ }^{6}$ Kovaleski, S.K., et al., "A Review of Testing of Hollow Cathodes for the International Space Station Plasma Contactor," IEPC Paper 01-271, October 2001.

${ }^{7}$ Soulas, G.C., Patterson, M.J., and Haag, T.W., "Performance Evaluation of $40 \mathrm{~cm}$ Ion Optics for the NEXT Ion Engine," AIAA Paper 2002-3834, July 2002.

${ }^{8}$ Pinero, L.R., Patterson, M.J., and Satterwhite, V.E., "Power Console Development for NASA's Electric Propulsion Outreach Program," IEPC Paper 93-250, September 1993.

${ }^{9}$ Polk, et al., "An Overview of the Results from an 8200 Hour Wear Test of the NSTAR Ion Thruster," AIAA Paper 99-2446, June 1999.

${ }^{10}$ Anderson, J.R., et al., "Results of an On-going Long Duration Ground Test of the DS1 Flight Spare Ion Engine," AIAA Paper 99-2857, June 1999.

${ }^{11}$ Polk, J.E., et al., “A 1000-Hour Wear Test of the NASA NSTAR Ion Thruster,” AIAA Paper 96-2717, July 1996.

${ }^{12}$ Patterson, M.J., Haag, T.W., and Hovan, S.A., "Performance of the NASA $30 \mathrm{~cm}$ Ion Thruster," IEPC Paper 93-108, September 1993.

${ }^{13}$ Sovey, J.S., "Improved Ion Containment Using a Ring-Cusp Ion Thruster," Journal of Spacecraft and Rockets, vol. 21, no. 5, September-October 1984, p. 489.

${ }^{14}$ Soulas, G.C., et al, "Status of the NEXT Ion Engine Wear Test," AIAA Paper 2003-4863, July 2003.

${ }^{15}$ Soulas, G.C., "Performance of Titanium Optics on a NASA $30 \mathrm{~cm}$ Ion Thruster," AIAA Paper 2000-3814, July 2000.

${ }^{16}$ Kamhawi, et al., "NEXT Ion Engine 2000 Hour Wear Test Plume and Erosion Results," AIAA Paper 20043792, July 2004.

${ }^{17}$ Hoskins, A., et al., "Development Status of the NEXT Prototype Model 40-cm Ion Thruster," AIAA Paper 2004-4111, July 2004.

${ }^{18}$ Kovaleski, S.D., "Life Model of Hollow Cathodes Using a Barium Calcium Aluminate Impregnated Tungsten Emitter," IEPC Paper No. 01-276, October 2001.

${ }^{19}$ Brophy, J.R., et al., "Numerical Simulations of Ion Thruster Accelerator Grid Erosion," AIAA Paper 20024261, July 2002.

${ }^{20}$ Emhoff, J.W. and Boyd, I.D., "Grid Erosion Modeling of the NEXT Ion Thruster Optics," AIAA Paper 20034868, July 2003.

${ }^{21}$ Farnell, C.C., Williams, J.D., and Wilbur P.J., "NEXT Ion Optics Simulation via ffx," AIAA Paper 20034869, July 2003. 
Table 1. NEXT wear test throttle table.

\begin{tabular}{|c|c|c|c|c|c|c|}
\hline $\begin{array}{l}\text { Anticipated } \\
\text { Engine } \\
\text { Input } \\
\text { Power, }{ }^{a} \\
\text { kW }\end{array}$ & $\begin{array}{c}\text { Beam } \\
\text { Current, } \\
\text { A }\end{array}$ & $\begin{array}{c}\text { Beam } \\
\text { Voltage, } \\
\text { V }\end{array}$ & $\begin{array}{l}\text { Accelerator } \\
\text { Voltage, V }\end{array}$ & $\begin{array}{c}\text { Main } \\
\text { Plenum } \\
\text { Flow Rate, } \\
\text { sccm }\end{array}$ & $\begin{array}{c}\text { Discharge } \\
\text { Cathode } \\
\text { Flow Rate, } \\
\text { sccm }\end{array}$ & $\begin{array}{l}\text { Neutalizer } \\
\text { Flow Rate, } \\
\text { sccm }\end{array}$ \\
\hline 1.07 & 1.20 & 680 & -115 & 15.7 & 3.57 & 4.01 \\
\hline 1.28 & 1.20 & 850 & -125 & 15.7 & 3.57 & 4.01 \\
\hline 1.49 & 1.20 & 1020 & -175 & 15.7 & 3.57 & 4.01 \\
\hline 1.68 & 1.20 & 1180 & -200 & 15.7 & 3.57 & 4.01 \\
\hline 1.94 & 1.20 & 1400 & -220 & 15.7 & 3.57 & 4.01 \\
\hline 2.14 & 1.20 & 1570 & -235 & 15.7 & 3.57 & 4.01 \\
\hline 2.42 & 1.20 & 1800 & -250 & 15.7 & 3.57 & 4.01 \\
\hline 2.40 & 2.00 & 1020 & -175 & 27.1 & 3.87 & 4.41 \\
\hline 2.71 & 2.00 & 1180 & -200 & 27.1 & 3.87 & 4.41 \\
\hline 3.15 & 2.00 & 1400 & -220 & 27.1 & 3.87 & 4.41 \\
\hline 3.49 & 2.00 & 1570 & -235 & 27.1 & 3.87 & 4.41 \\
\hline 3.96 & 2.00 & 1800 & -250 & 27.1 & 3.87 & 4.41 \\
\hline 3.18 & 2.70 & 1020 & -175 & 37.6 & 4.26 & 4.75 \\
\hline 3.61 & 2.70 & 1180 & -200 & 37.6 & 4.26 & 4.75 \\
\hline 4.20 & 2.70 & 1400 & -220 & 37.6 & 4.26 & 4.75 \\
\hline 4.66 & 2.70 & 1570 & -235 & 37.6 & 4.26 & 4.75 \\
\hline 5.30 & 2.70 & 1800 & -250 & 37.6 & 4.26 & 4.75 \\
\hline 4.12 & 3.10 & 1180 & -200 & 43.5 & 4.54 & 4.95 \\
\hline 4.80 & 3.10 & 1400 & -220 & 43.5 & 4.54 & 4.95 \\
\hline 5.33 & 3.10 & 1570 & -235 & 43.5 & 4.54 & 4.95 \\
\hline 6.06 & 3.10 & 1800 & -250 & 43.5 & 4.54 & 4.95 \\
\hline 4.66 & 3.52 & 1180 & -200 & 49.6 & 4.87 & 5.16 \\
\hline 5.42 & 3.52 & 1400 & -220 & 49.6 & 4.87 & 5.16 \\
\hline 6.03 & 3.52 & 1570 & -235 & 49.6 & 4.87 & 5.16 \\
\hline $6.85^{\mathrm{e}}$ & $3.52^{\mathrm{e}}$ & $1800^{\mathrm{e}}$ & $-250 /-210^{\mathrm{e}, \mathrm{f}}$ & $49.6^{\mathrm{e}}$ & $4.87^{\mathrm{e}}$ & $5.16^{\mathrm{e}}$ \\
\hline $\begin{array}{c}{ }^{\mathrm{a}} \text { Nom } \\
{ }^{\mathrm{b}} \mathrm{Pow} \\
{ }^{\mathrm{c}} \mathrm{Mai} \\
{ }^{\mathrm{d}} \mathrm{Neu} \\
\text { sccm } \\
{ }^{\mathrm{e}} \mathrm{Wea} \\
{ }^{\mathrm{f}} \text { Acce }\end{array}$ & $\begin{array}{l}\text { al values. } \\
\text { supply vo } \\
\text { to-discharg } \\
\text { alizer flow } \\
\text { test operati } \\
\text { rator volta }\end{array}$ & $\begin{array}{l}\text { ge. } \\
\text { cathode flow } \\
\text { ith beam extr } \\
\text { point. } \\
\text { increased fr } \\
\text { current was? }\end{array}$ & $\begin{array}{l}\text { plit selected to } \\
\text { ction; without } \\
\mathrm{m}-250 \mathrm{~V} \text { to }-2\end{array}$ & $\begin{array}{l}\text { esult in a } 23.5 \text { - } \\
0 \mathrm{~V} \text { just at the }\end{array}$ & $\begin{array}{l}\mathrm{V} \text { discharge } \\
\mathrm{d} \text { for ignition, } \\
\text { art of the wear }\end{array}$ & $\begin{array}{l}\text { tage. } \\
\text { w is set to } 6.00 \\
\text { t. }\end{array}$ \\
\hline
\end{tabular}


Table 2. Wear test interruptions.

\begin{tabular}{|c|c|c|}
\hline $\begin{array}{c}\text { Test } \\
\text { Segment }\end{array}$ & $\begin{array}{l}\text { Accumulated } \\
\text { Time at Full } \\
\text { Power, h }\end{array}$ & Test Interruption Cause \\
\hline 1 & 0.4 & Data acquisition system communications error \\
\hline 2 & 4 & Data acquisition system communications error \\
\hline 3 & 7 & Data acquisition system communications error \\
\hline 4 & 14 & Data acquisition system communications error \\
\hline 5 & 25 & Data acquisition system communications error \\
\hline 6 & 40 & Power console accelerator power supply failure \\
\hline 7 & 64 & Power console cutback discharge current for unknown reason \\
\hline 8 & 127 & Data acquisition system digital hardware anomaly \\
\hline 9 & 179 & Power console cutback discharge current for unknown reason \\
\hline 10 & 218 & Data acquisition system component failure \\
\hline 11 & 258 & Data acquisition system digital hardware anomaly \\
\hline 12 & 317 & Power console removed beam voltage for unknown reason \\
\hline 13 & 436 & Data acquisition system communications error \\
\hline 14 & 549 & Performance test \\
\hline 15 & 564 & Performance test \\
\hline 16 & 627 & Performance test \\
\hline 17 & 645 & Performance test \\
\hline 18 & 661 & Performance test \\
\hline 19 & 677 & Performance test \\
\hline 20 & 768 & Power console varied accelerator voltage for unknown reasons \\
\hline 21 & 815 & Power console varied accelerator voltage for unknown reasons \\
\hline 22 & 1053 & Facility pressure spike \\
\hline 23 & 1084 & Power console removed beam voltage for unknown reason \\
\hline 24 & 1110 & Performance test \\
\hline 25 & 1130 & Performance test \\
\hline 26 & 1148 & Performance test \\
\hline 27 & 1164 & Performance test \\
\hline 28 & 1166 & Power console removed beam voltage for unknown reason \\
\hline 29 & 1225 & $\begin{array}{l}\text { Facility pressure increase; cryogenic pump eventually failed; } \\
\text { only } 11 \text { pumps operational }\end{array}$ \\
\hline 30 & 1245 & Performance test \\
\hline 31 & 1308 & Performance test \\
\hline 32 & 1411 & $\begin{array}{l}\text { Facility cryogenic pump failed; another repaired; } 11 \text { pumps still } \\
\text { operational }\end{array}$ \\
\hline 33 & 1735 & Power console zeroed discharge power for unknown reason \\
\hline 34 & 1968 & Facility pressure increase \\
\hline 35 & 2014 & $\begin{array}{l}\text { Facility pressure unstable; cryogenic pump eventually failed; } 10 \\
\text { pumps operational }\end{array}$ \\
\hline 36 & 2038 & Post-test performance test \\
\hline
\end{tabular}


Table 3. NEXT service life assessment of critical ion engine components.

\begin{tabular}{|c|c|c|c|}
\hline $\begin{array}{l}\text { Ion Engine } \\
\text { Component }\end{array}$ & Failure Mechanism & $\begin{array}{l}\text { Propellant } \\
\text { Throughput, } \\
\text { kg }\end{array}$ & Analysis Method \\
\hline $\begin{array}{l}\text { Discharge } \\
\text { chamber flake } \\
\text { retention material }\end{array}$ & $\begin{array}{c}\text { Unclearable grid electrical } \\
\text { short }\end{array}$ & $>405$ & Flake retention tests \\
\hline Cathode inserts & $\begin{array}{l}\text { Depletion of low work } \\
\text { function material from } \\
\text { emission zone }\end{array}$ & $>405$ & Modeling, \\
\hline $\begin{array}{l}\text { Discharge cathode } \\
\text { and keeper }\end{array}$ & $\begin{array}{l}\text { Erosion through keeper } \\
\text { orifice plate thickness }\end{array}$ & 1840 & $\begin{array}{l}\text { Extrapolation of wear test data \& } \\
\text { sputter yield comparisons }\end{array}$ \\
\hline $\begin{array}{l}\text { Neutralizer } \\
\text { cathode and } \\
\text { keeper }^{\mathrm{c}}\end{array}$ & $\begin{array}{l}\text { Erosion through keeper } \\
\text { tube thickness }\end{array}$ & 587 & Extrapolation of wear test data \\
\hline \multirow{2}{*}{ Ion Optics $^{\mathrm{c}}$} & $\begin{array}{l}\text { Structural failure of } \\
\text { accelerator grid from } \\
\text { groove erosion }\end{array}$ & 750 & Extrapolation of wear test data \\
\hline & $\begin{array}{l}\text { Electron backstreaming } \\
\text { from aperture enlargement } \\
\text { of accelerator grid }\end{array}$ & $>405$ & Modeling ${ }^{\mathrm{a}, \mathrm{d}}$ \\
\hline
\end{tabular}




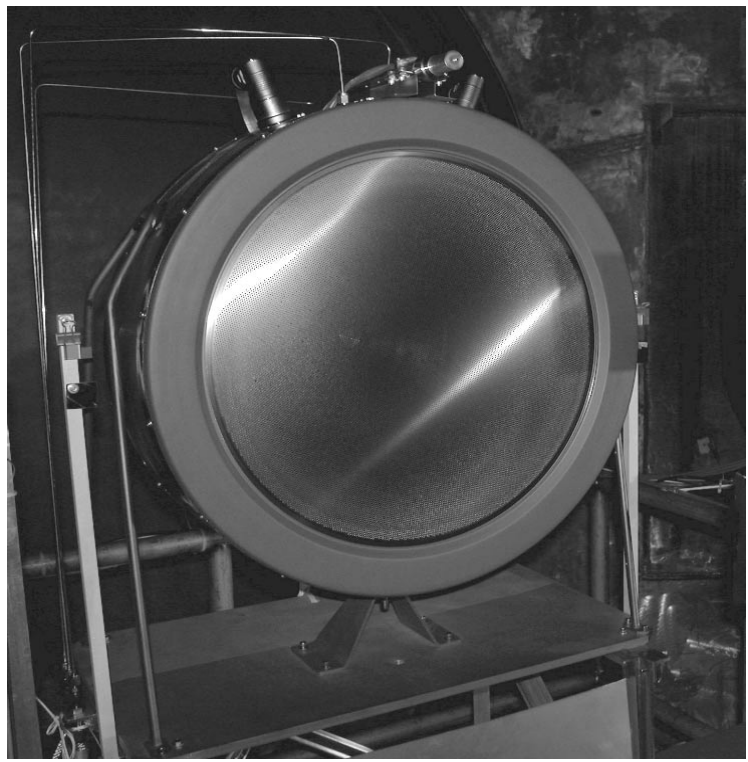

Figure 1. NEXT engineering model engine EM1.

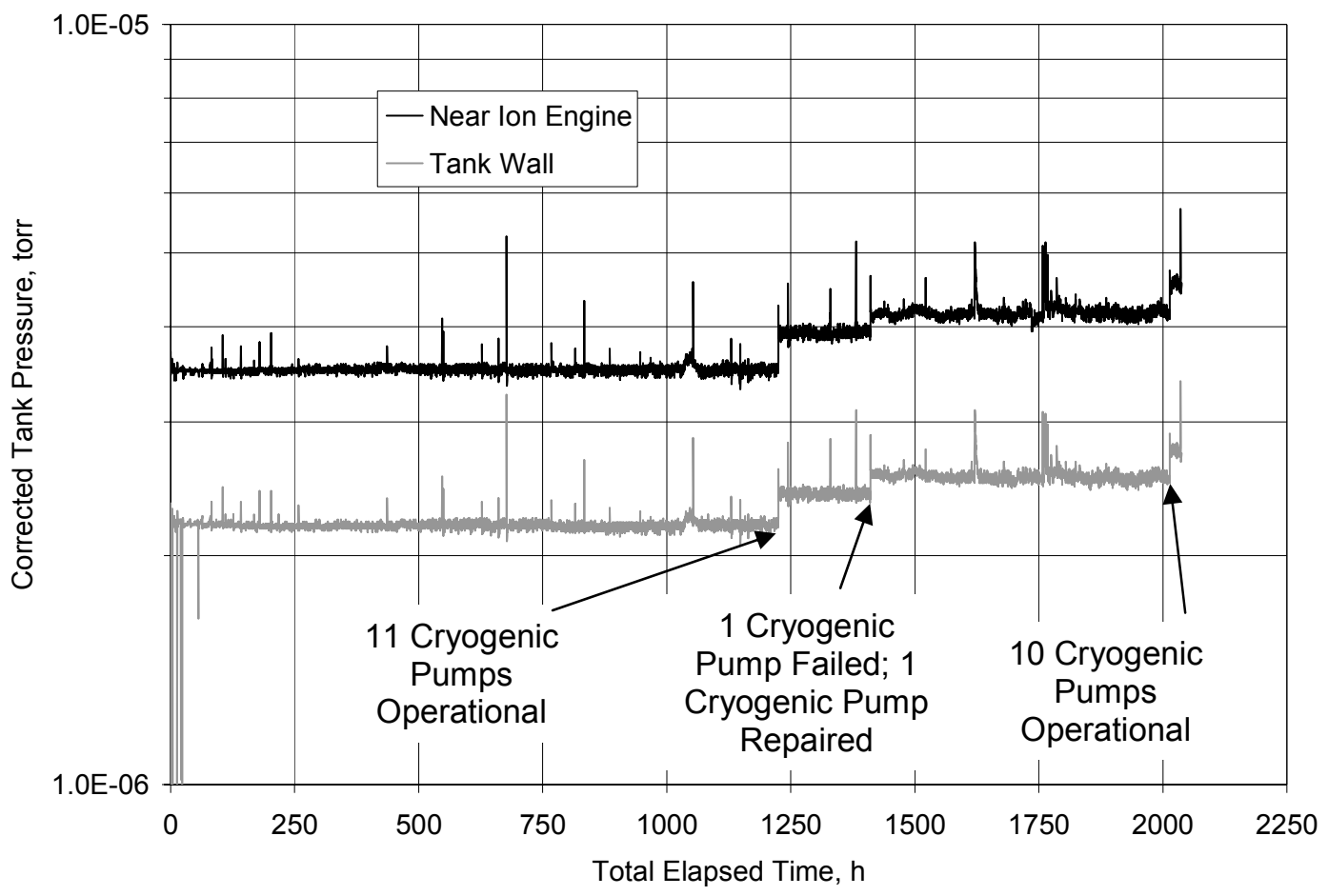

Figure 2. Corrected tank pressure as a function of time. 


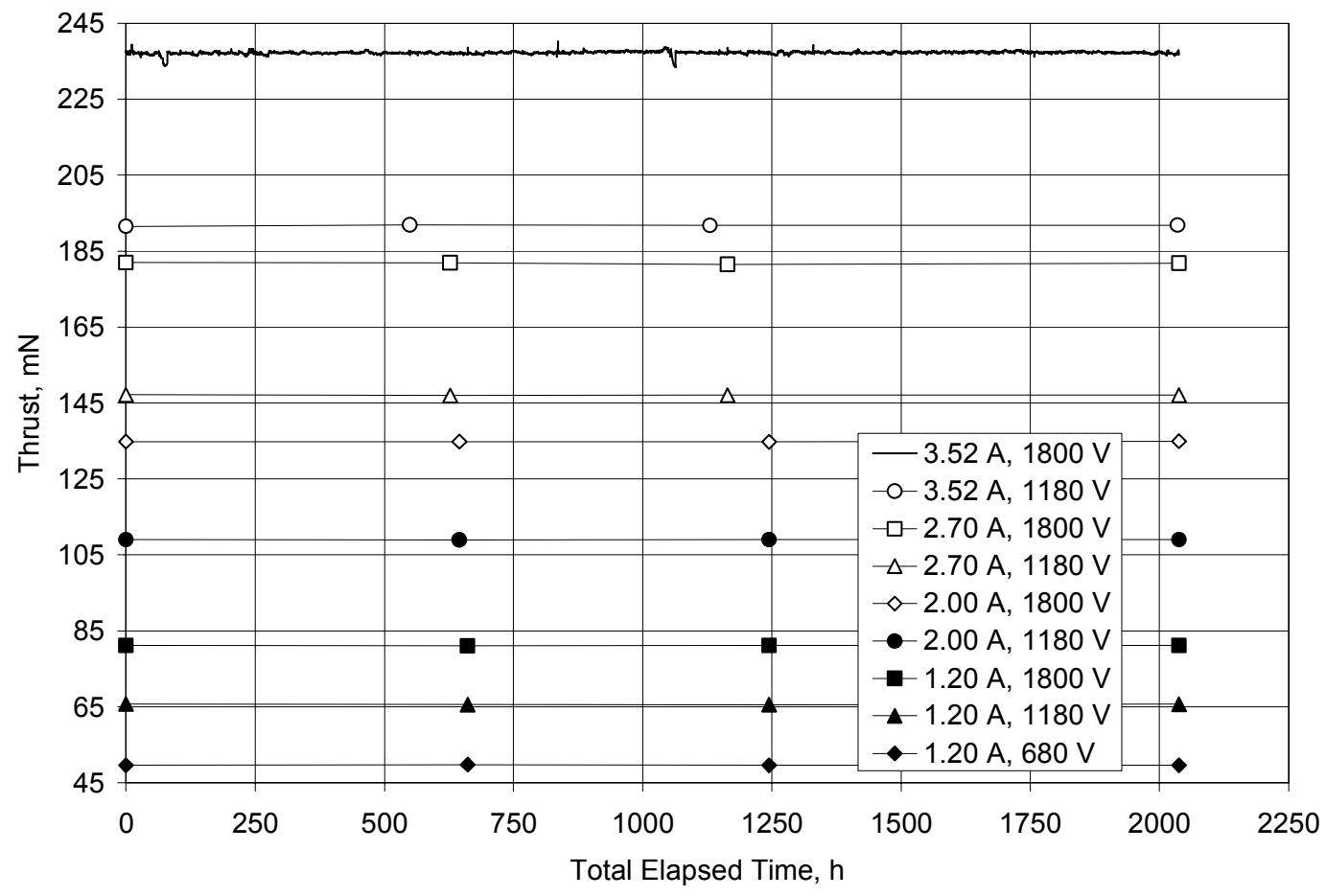

Figure 3. Calculated thrust as a function of time throughout the throttle table. Legend lists corresponding beam currents and beam power supply voltages.

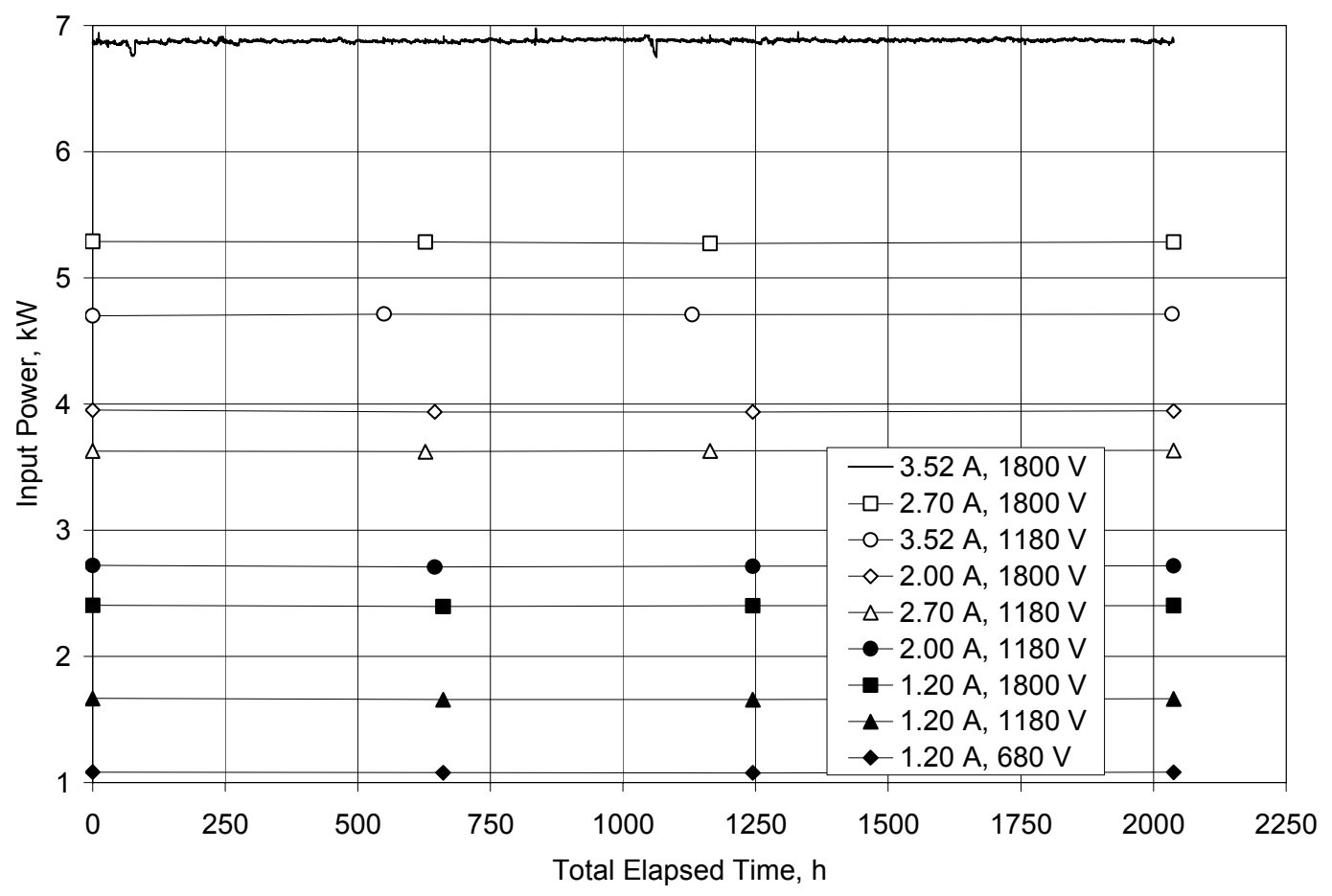

Figure 4. Thruster input power as a function of time throughout the throttle table. Legend lists corresponding beam currents and beam power supply voltages. 


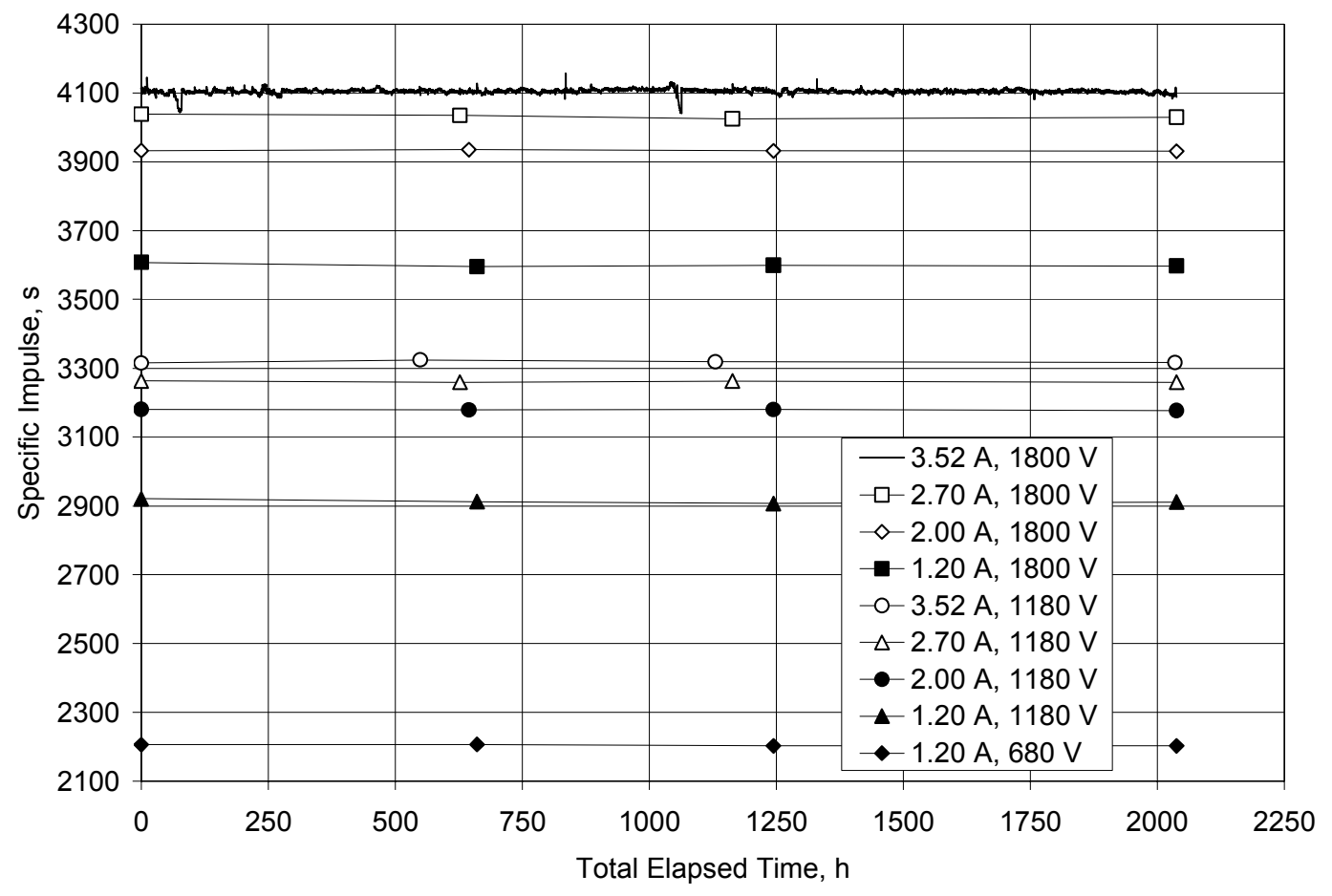

Figure 5. Specific impulse as a function of time throughout the throttle table. Legend lists corresponding beam currents and beam power supply voltages.

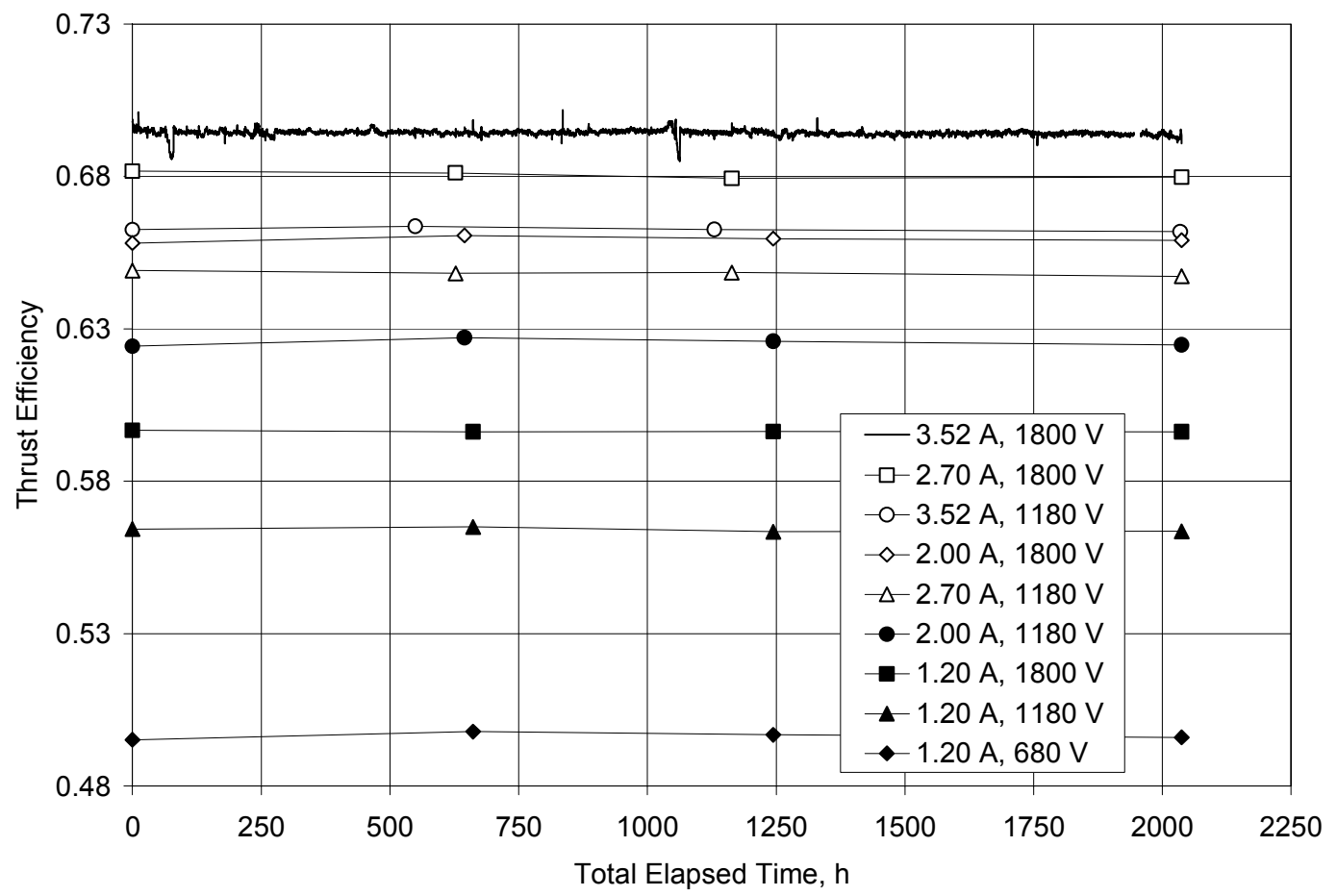

Figure 6. Thrust efficiency as a function of time throughout the throttle table. Legend lists corresponding beam currents and beam power supply voltages. 


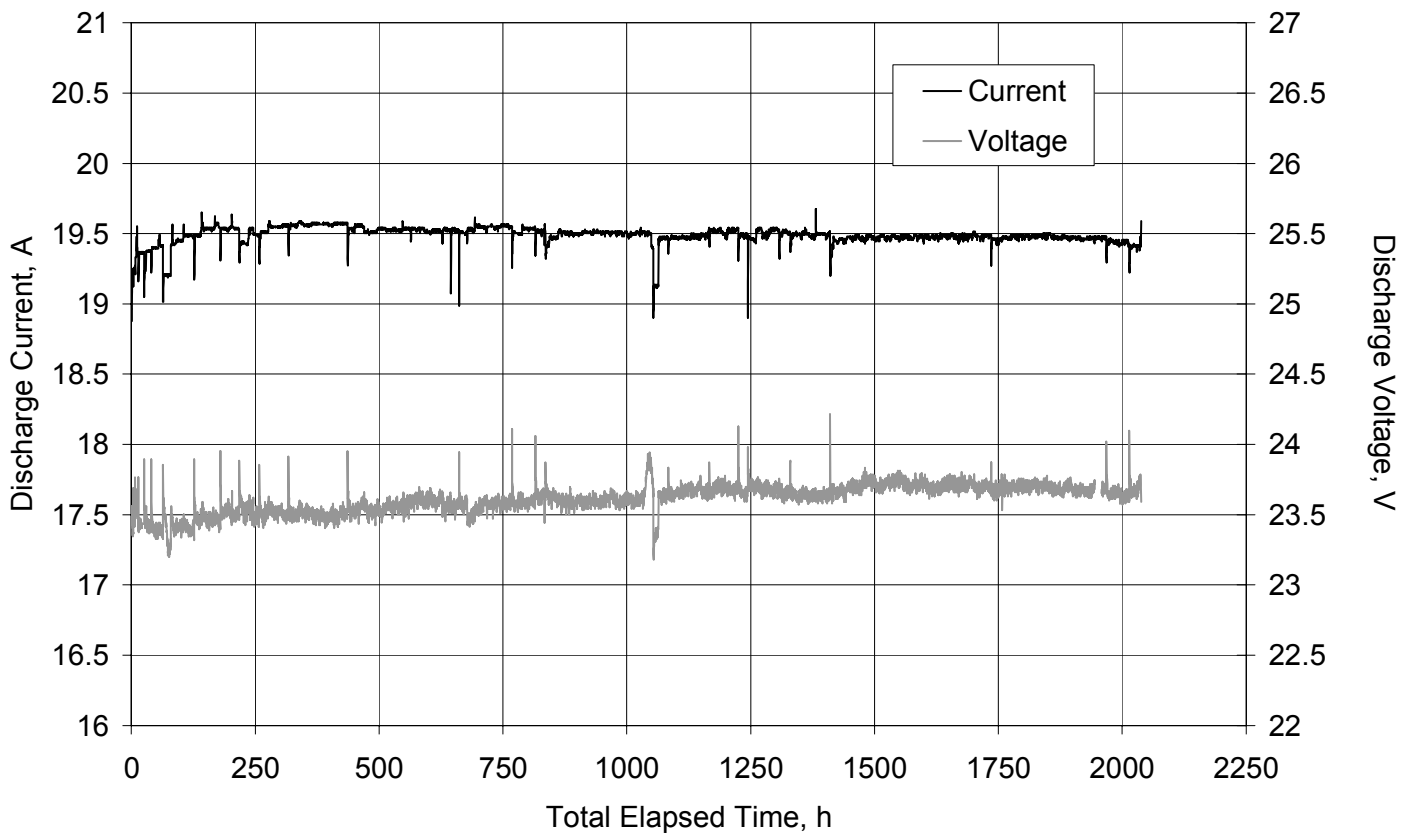

Figure 7. Discharge current and voltage as a function of time at full power (i.e. $6.9 \mathrm{~kW}$ ).

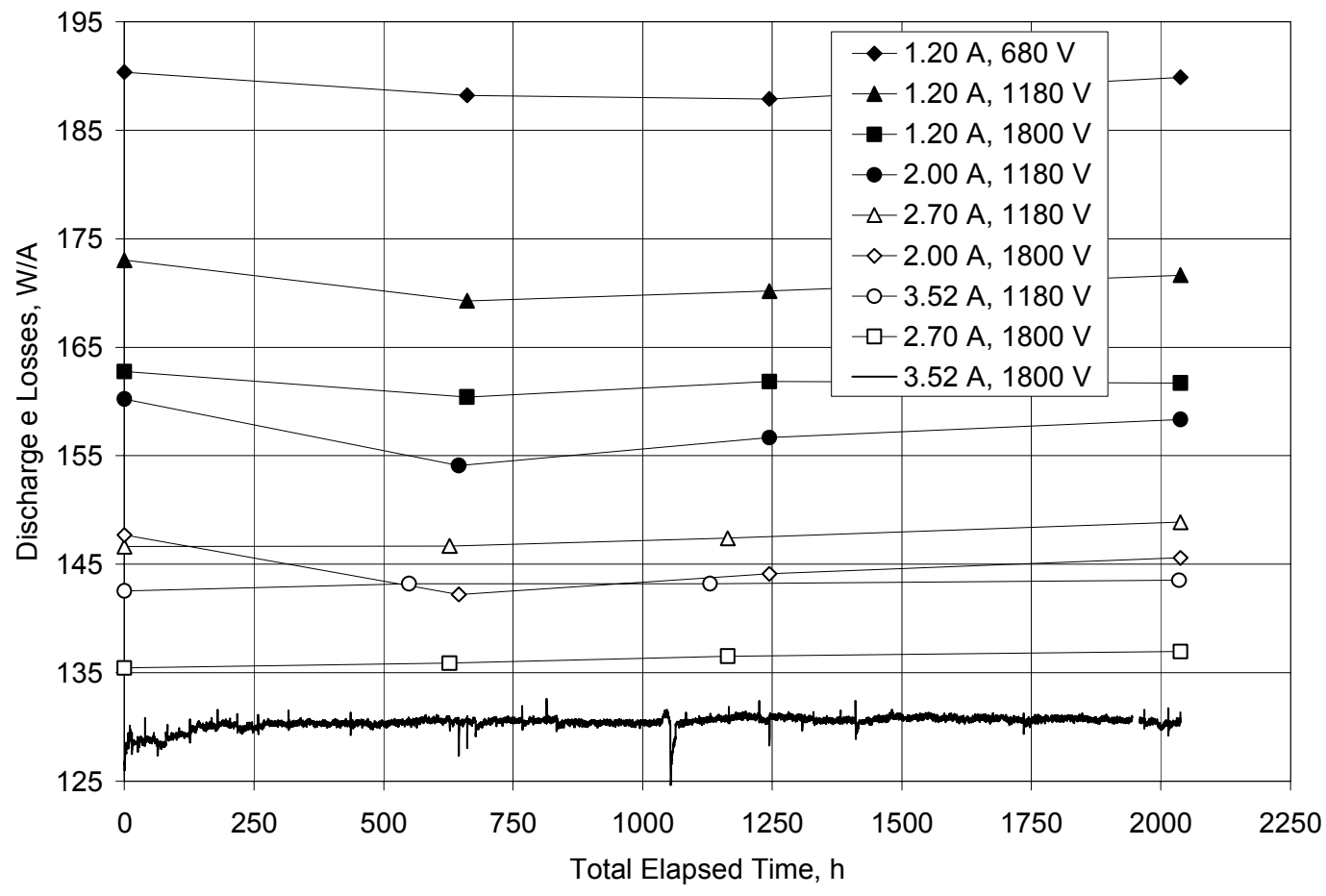

Figure 8. Discharge losses as a function of time throughout the throttle table. Legend lists corresponding beam currents and beam power supply voltages. 


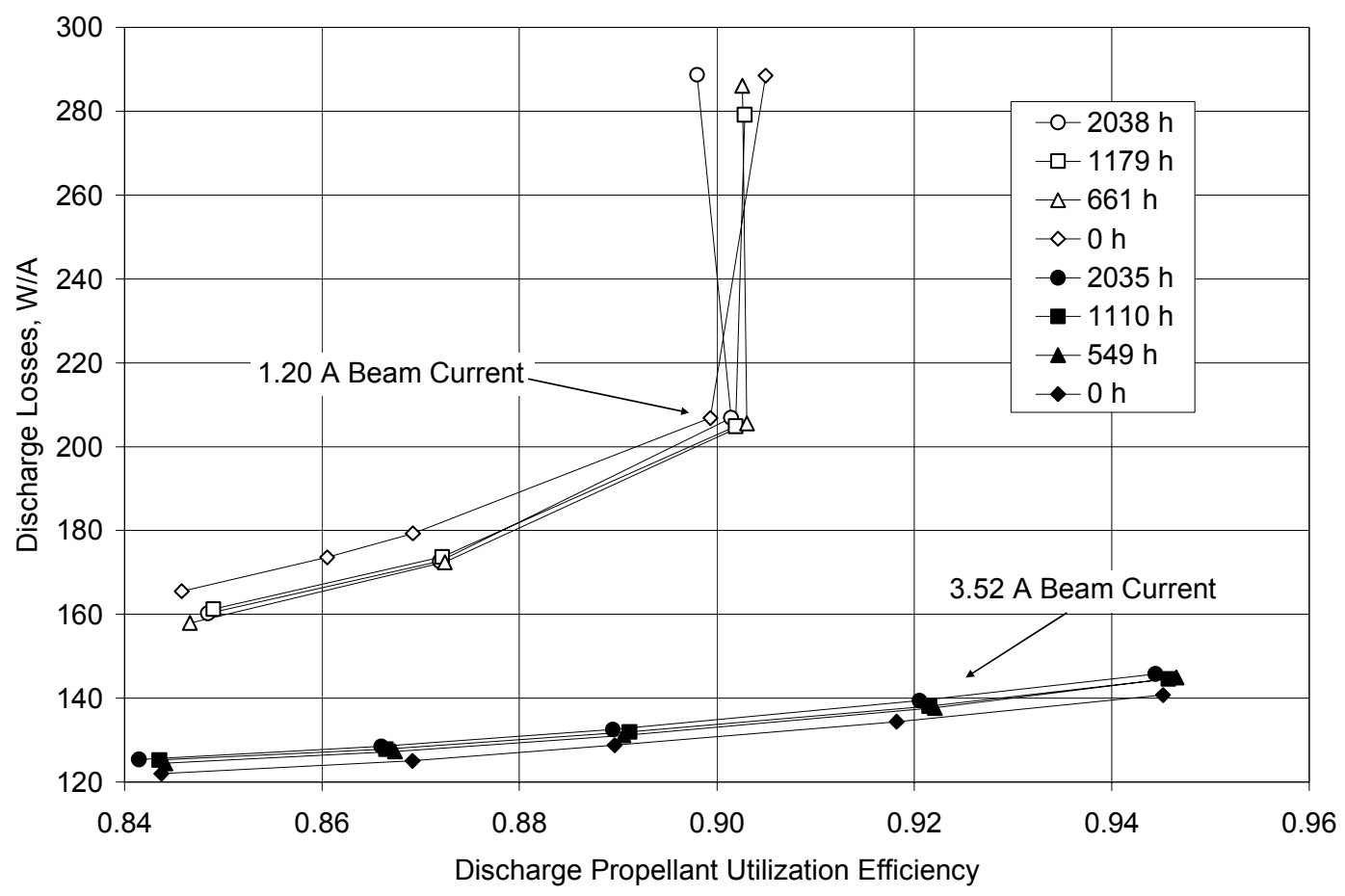

Figure 9. Discharge losses as a function of discharge propellant utilization efficiency throughout the wear test for beam currents of $1.20 \mathrm{~A}$ and $3.52 \mathrm{~A}$. Propellant utilization efficiencies include ingested flow from facility background pressure.

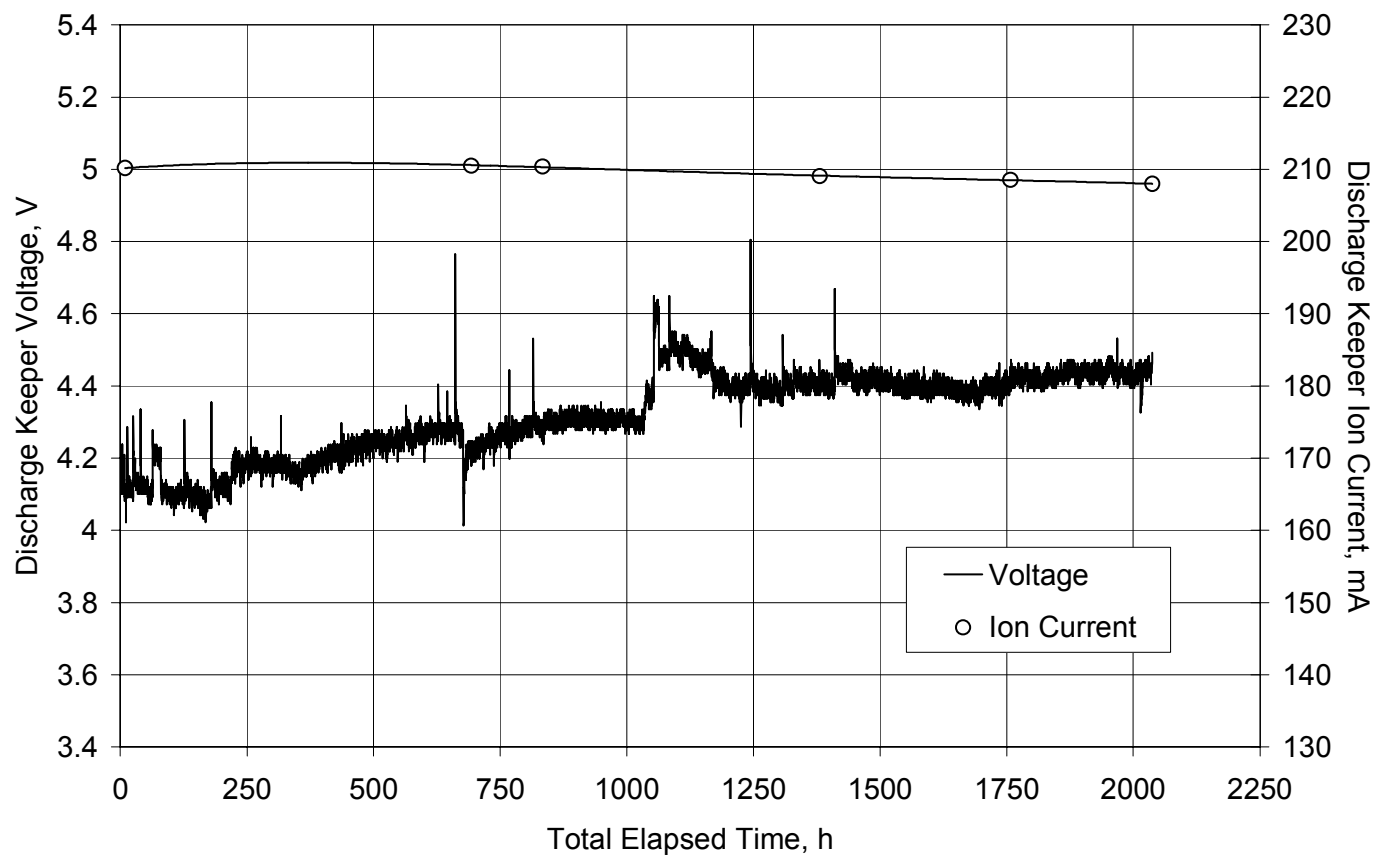

Figure 10. Discharge keeper voltage and ion current as a function of time at full power. Discharge keeper ion current was measured by biasing the keeper negative relative to the discharge cathode. 


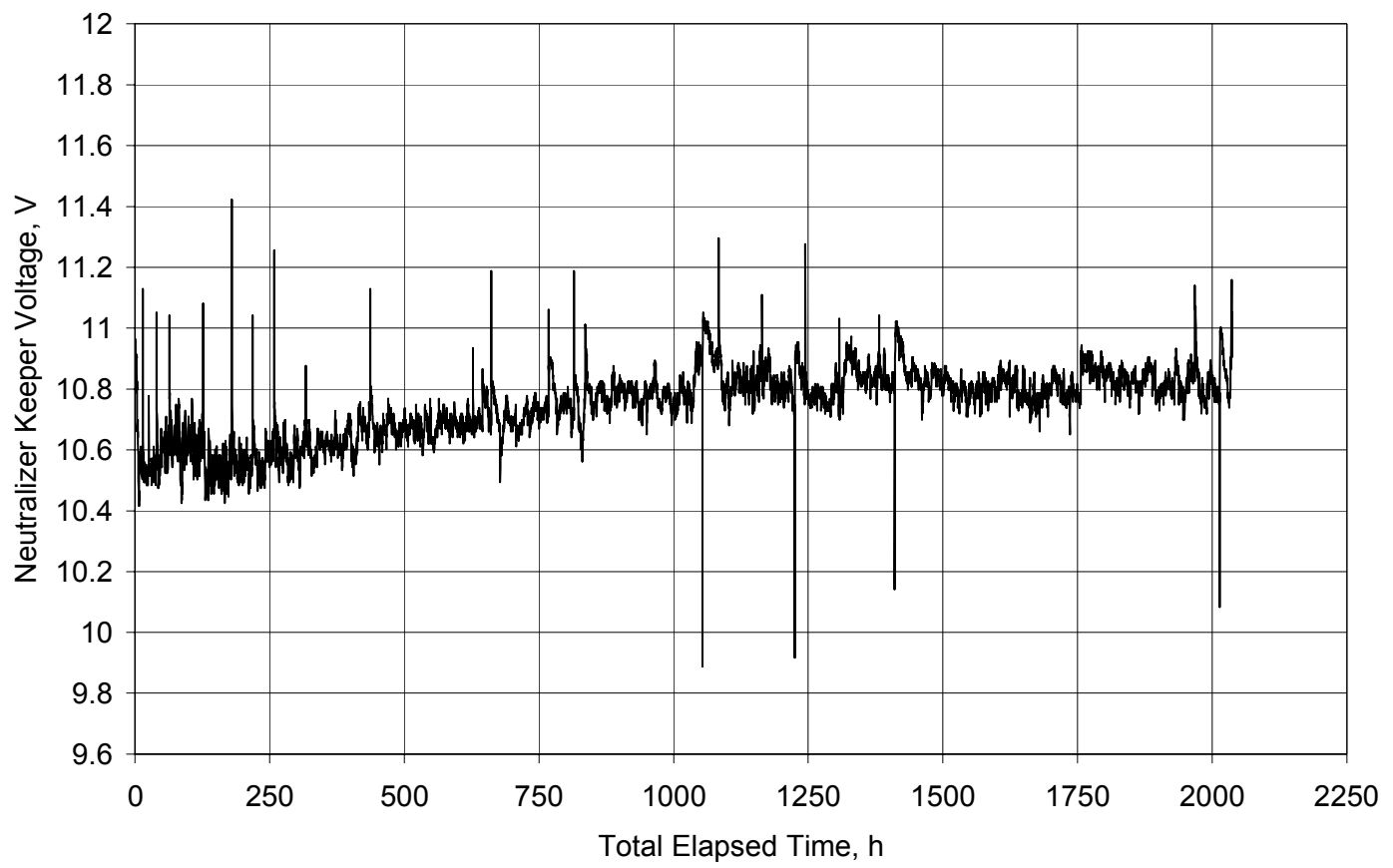

Figure 11. Neutralizer keeper voltage as a function of time throughout the wear test at full power.

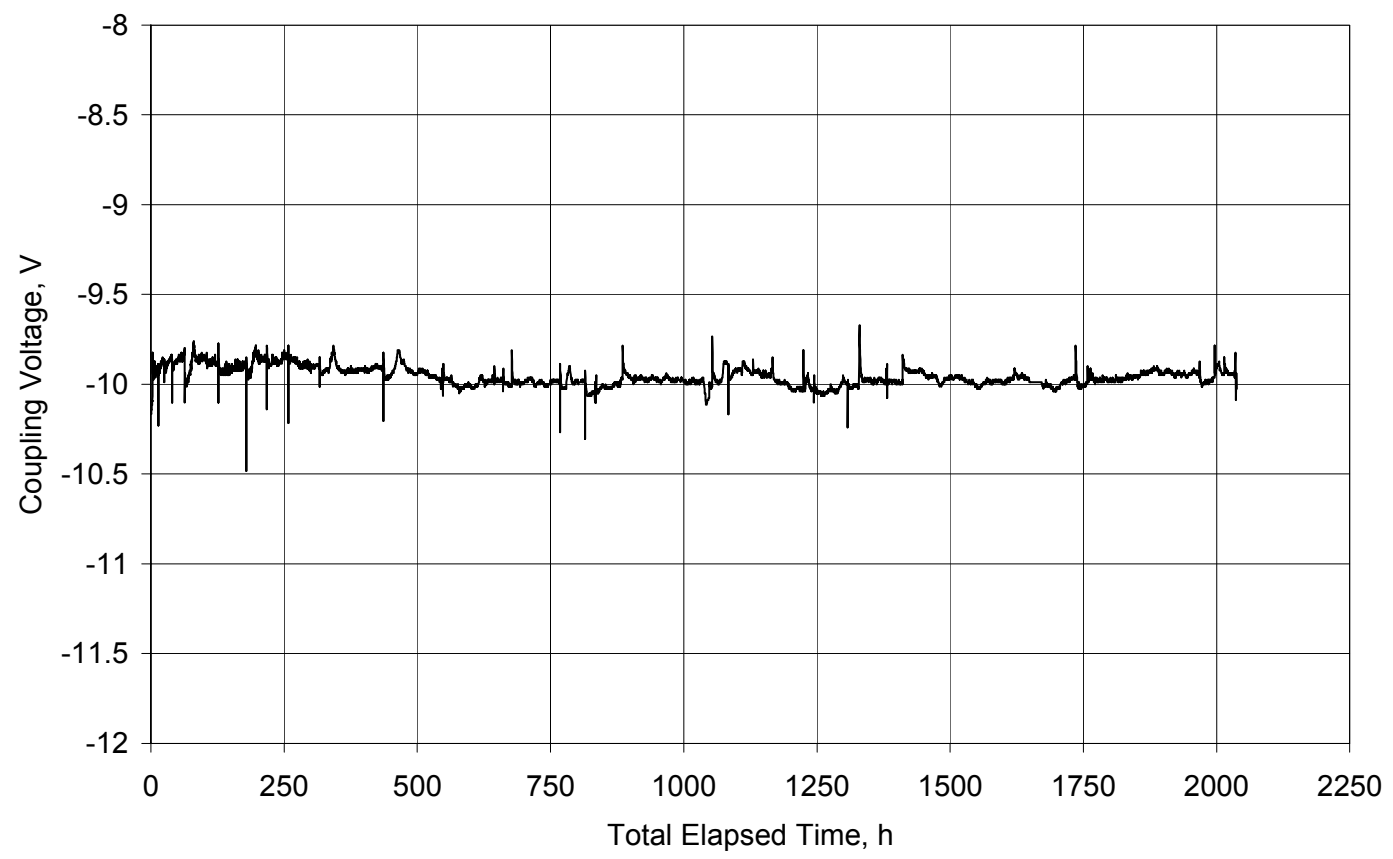

Figure 12. Coupling voltage as a function of time throughout the wear test at full power. 


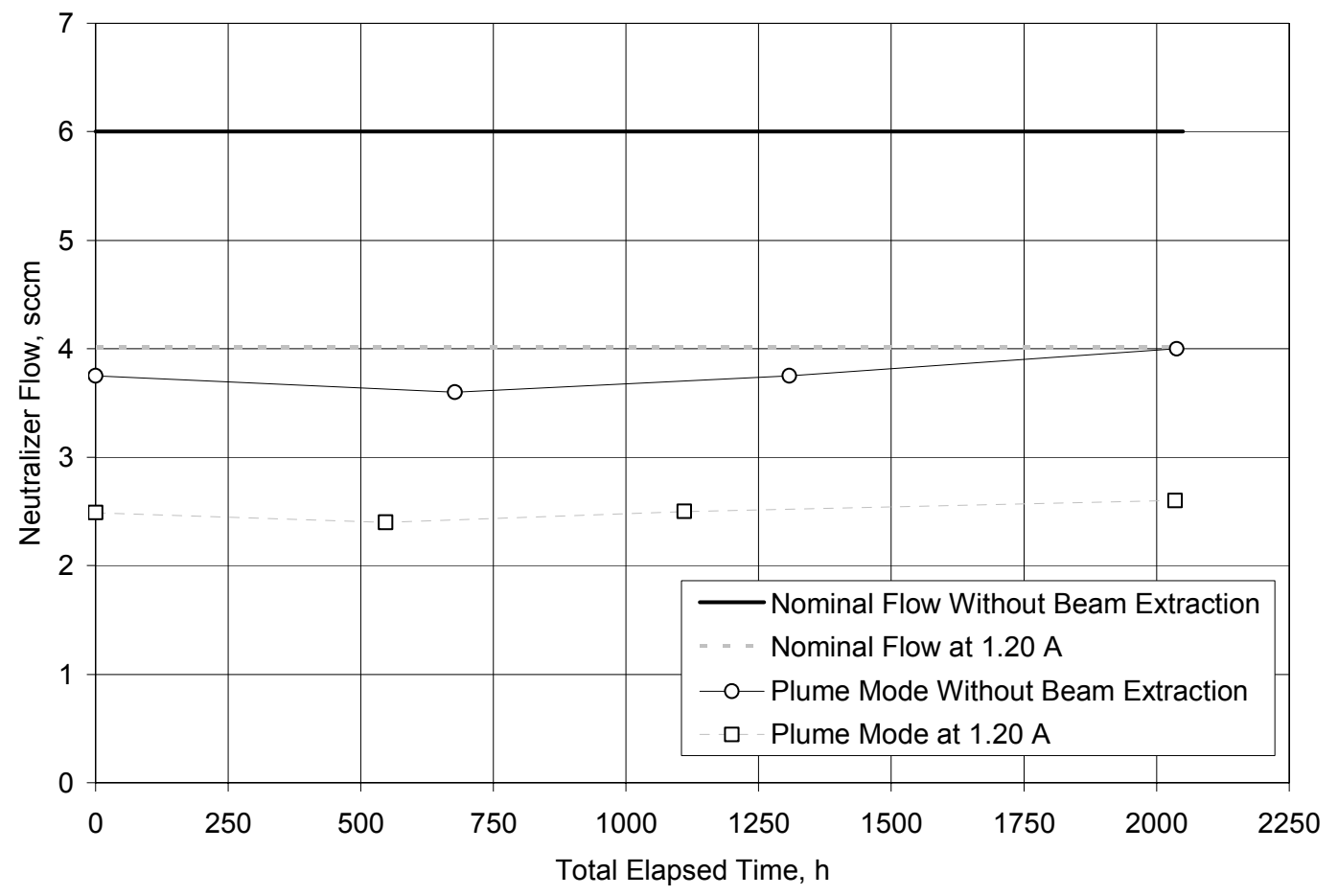

Figure 13. Plume mode neutralizer flow as a function of time throughout the wear test with beam extraction at $1.20 \mathrm{~A}$ and without beam extraction.

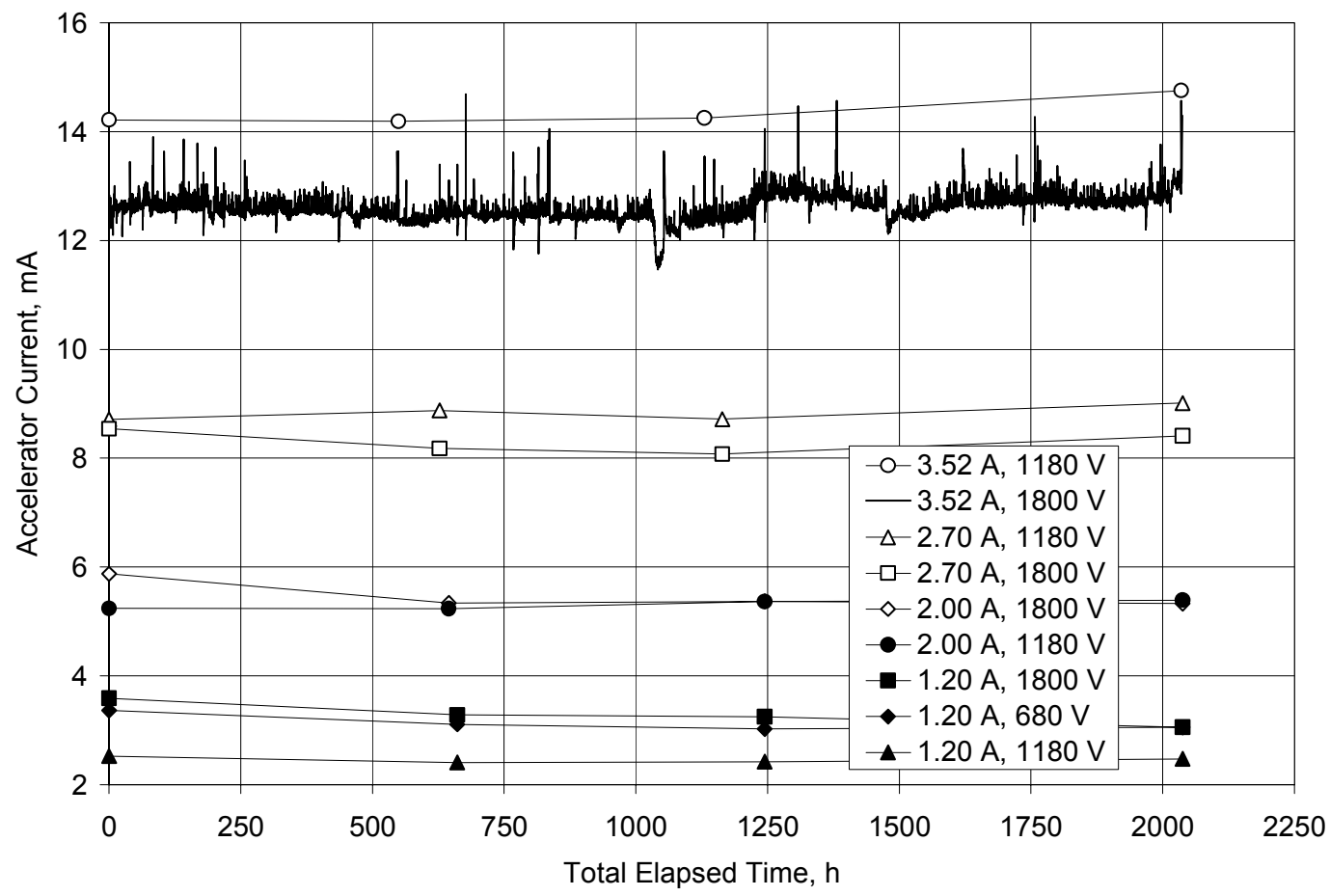

Figure 14. Accelerator currents as a function of time throughout the throttle table. Legend lists corresponding beam currents and beam power supply voltages. 


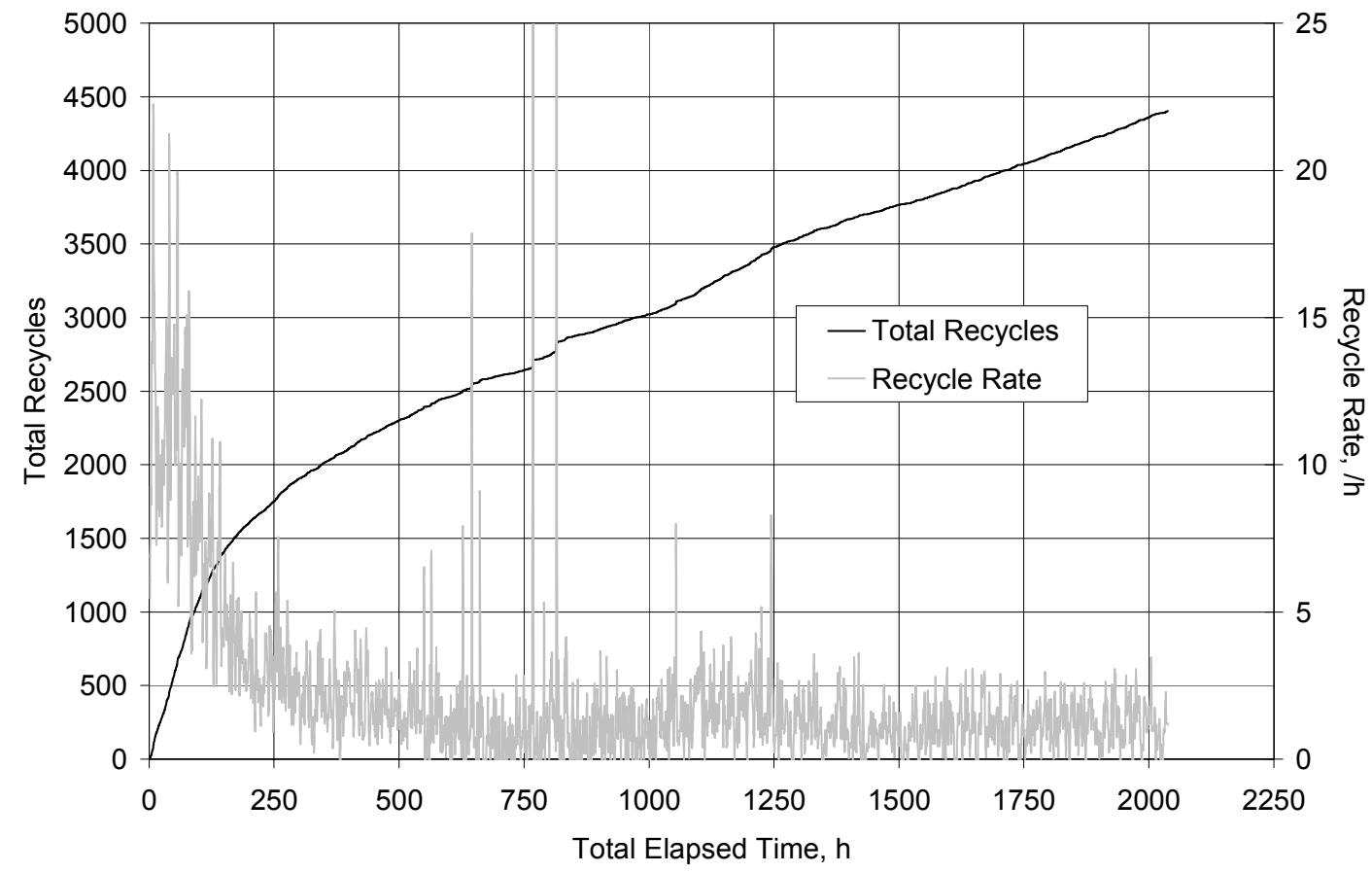

Figure 15. Total recycles and recycle rate as a function of time. Recycle rate is the slope of the total recycles versus time over a $3 \mathrm{~h}$ period.

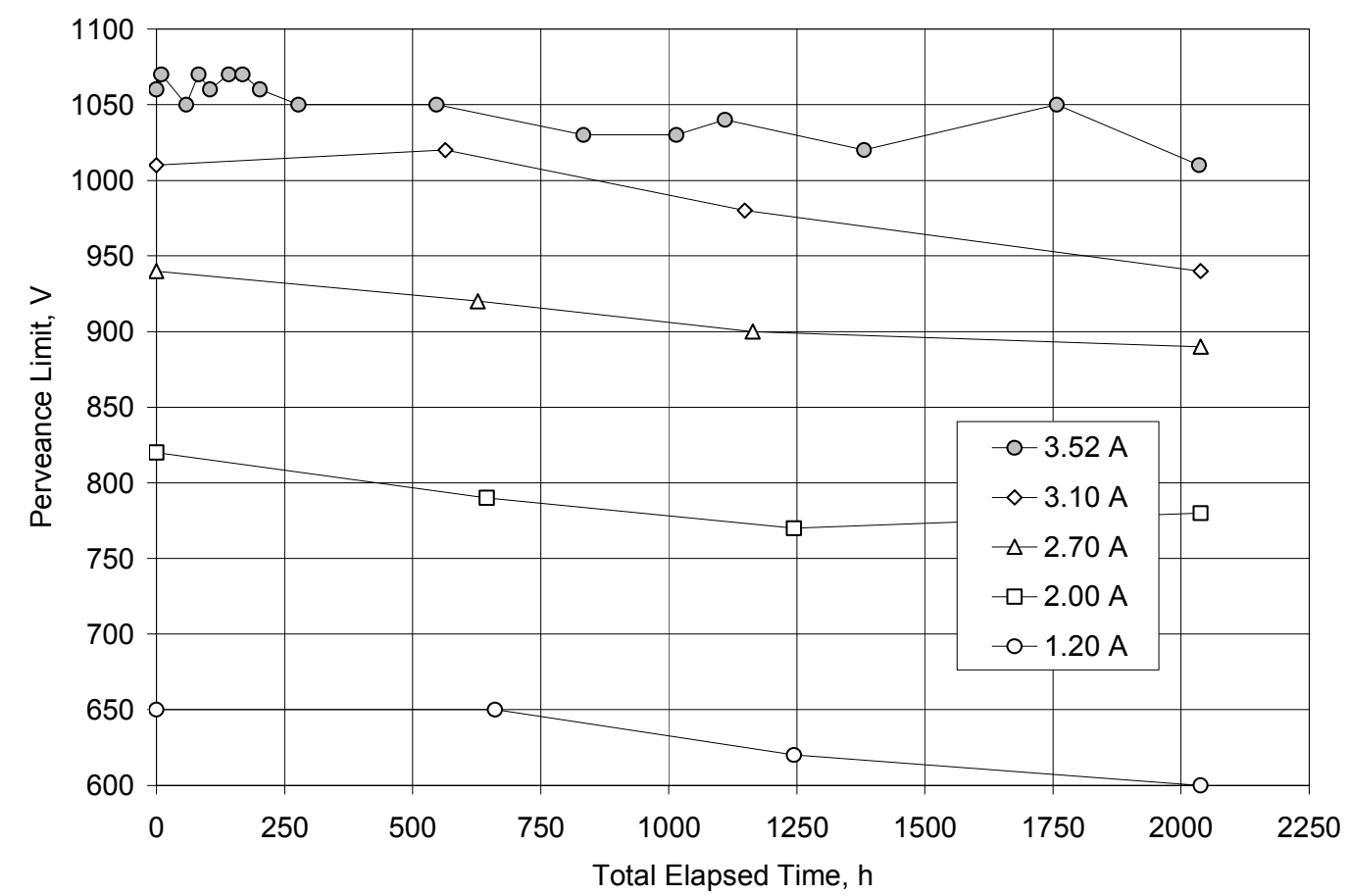

Figure 16. Perveance limit as a function of time throughout the throttle table. Legend lists corresponding beam currents. 


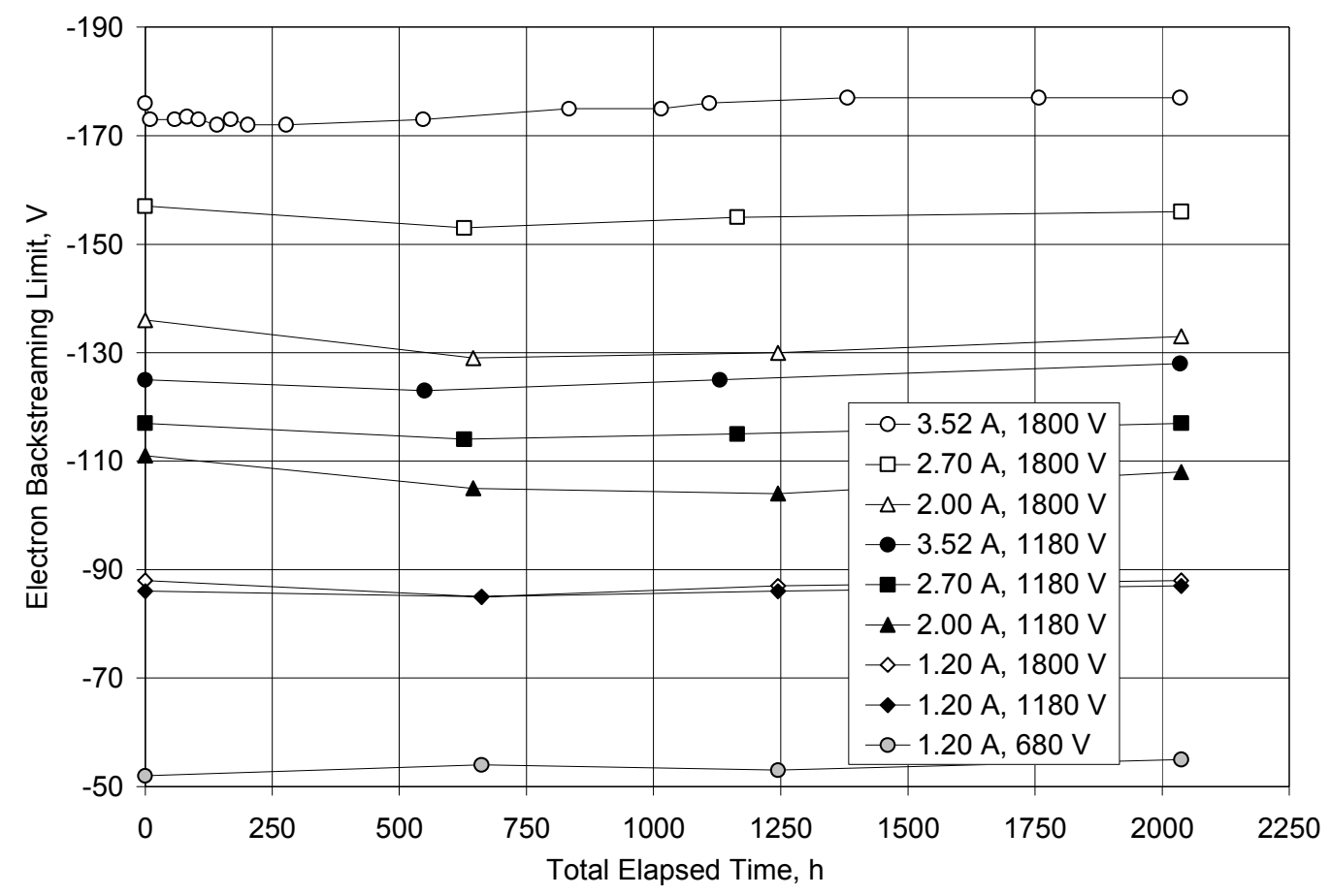

Figure 17. Electron backstreaming limit as a function of time throughout the throttle table. Legend lists corresponding beam currents and beam power supply voltages.

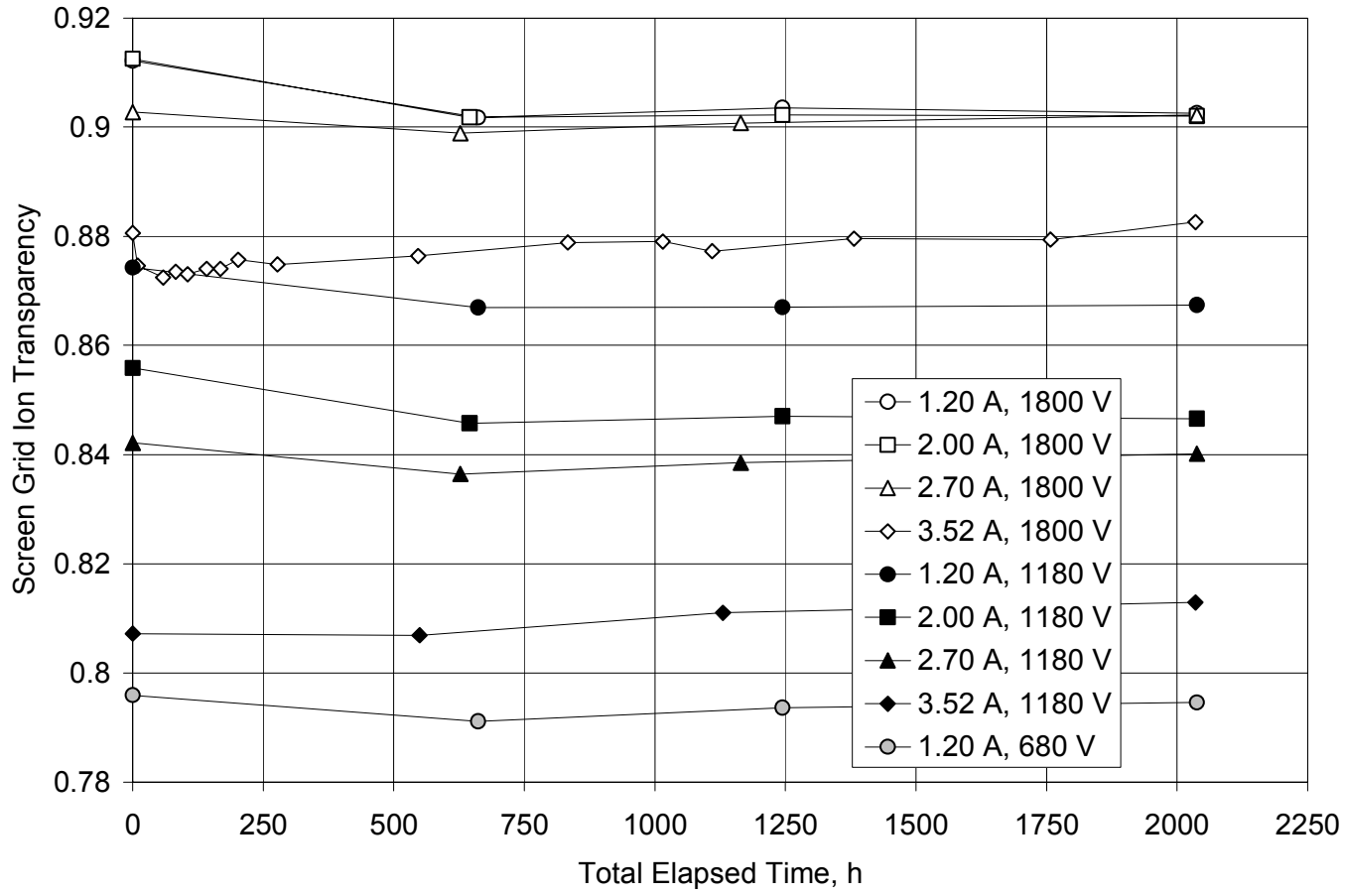

Figure 18. Screen grid ion transparency as a function of time throughout the throttle table. Legend lists corresponding beam currents and beam power supply voltages. 


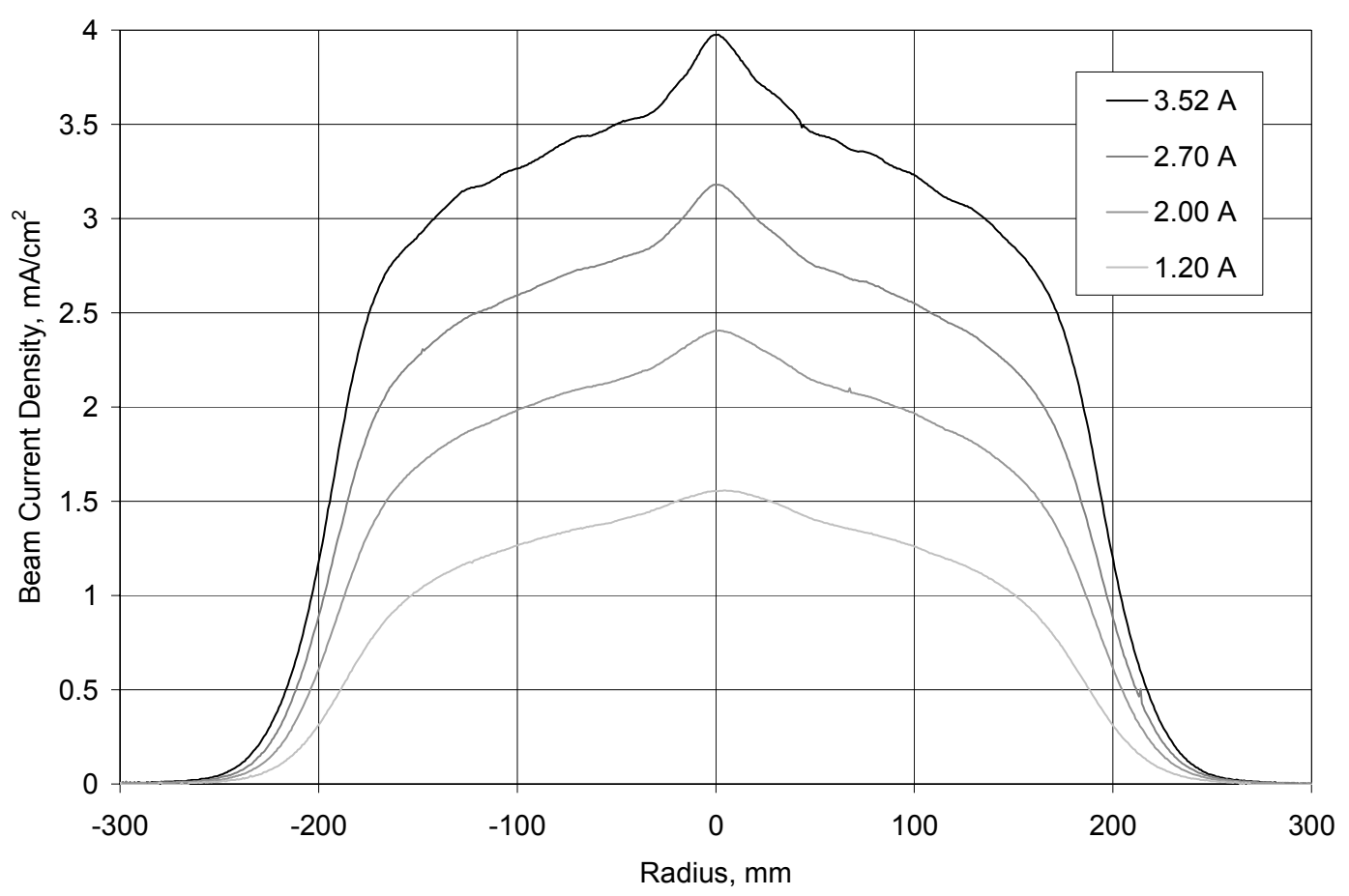

Figure 19. Post-test radial beam current density profiles. All data were obtained at a beam power supply voltage of $1800 \mathrm{~V}$ and $45 \mathrm{~mm}$ downstream of the ion optics' center.

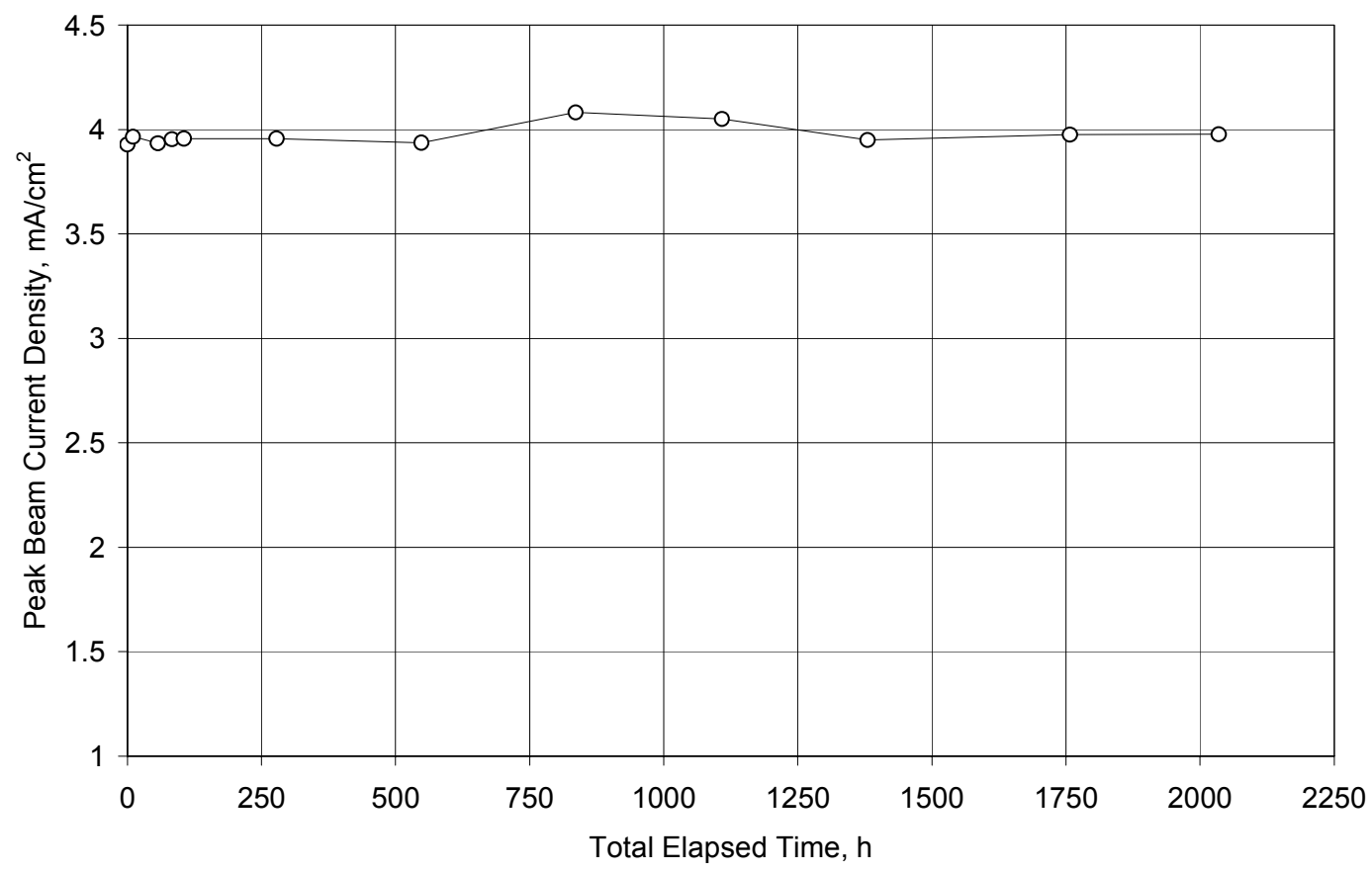

Figure 20. Peak beam current density as a function of time at full power. All data were obtained $45 \mathrm{~mm}$ downstream of the ion optics' center. 


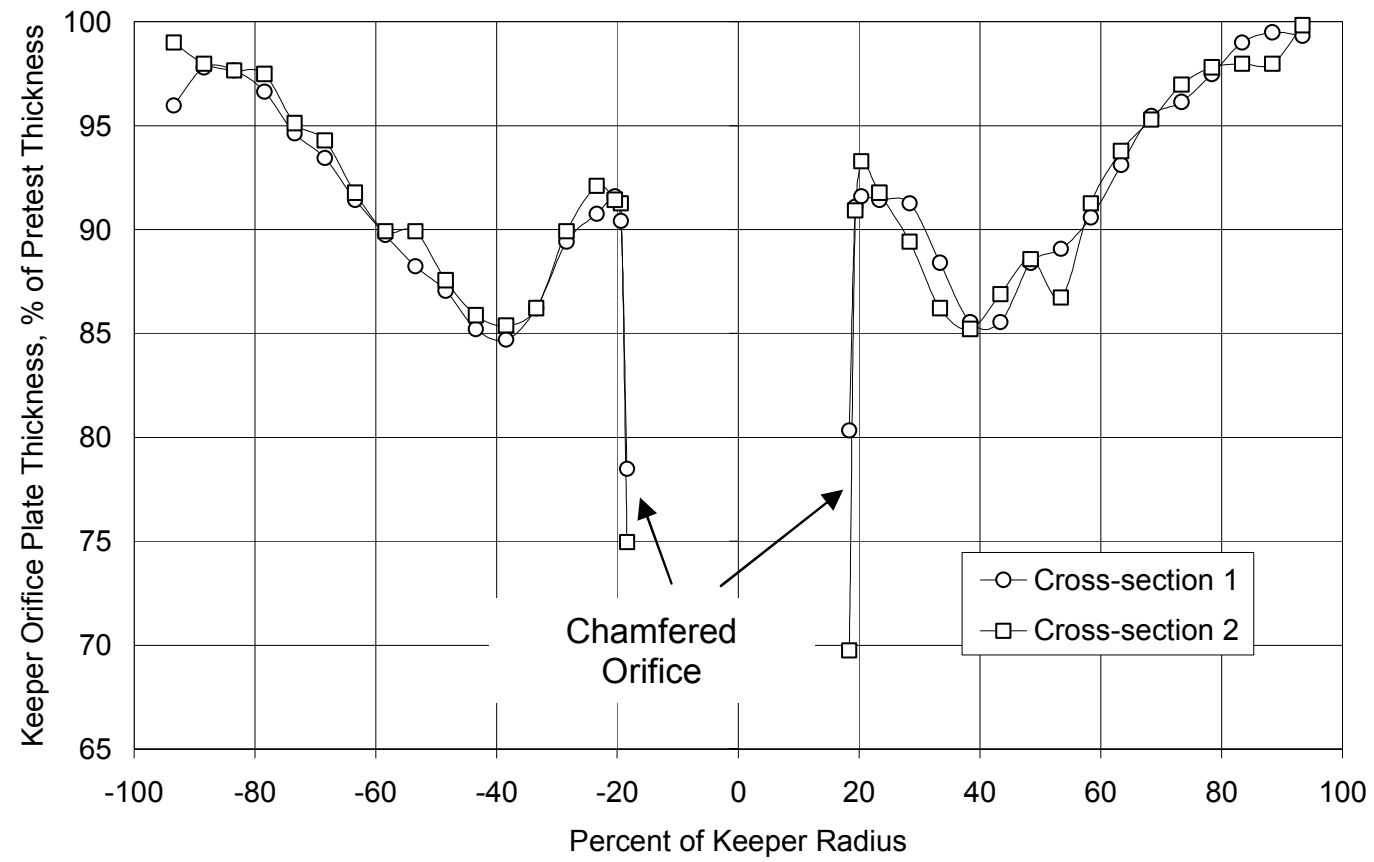

Figure 21. Post-test discharge keeper thickness as a function of keeper radius. Cross-sections 1 and 2 are clocked $90^{\circ}$ of each other.

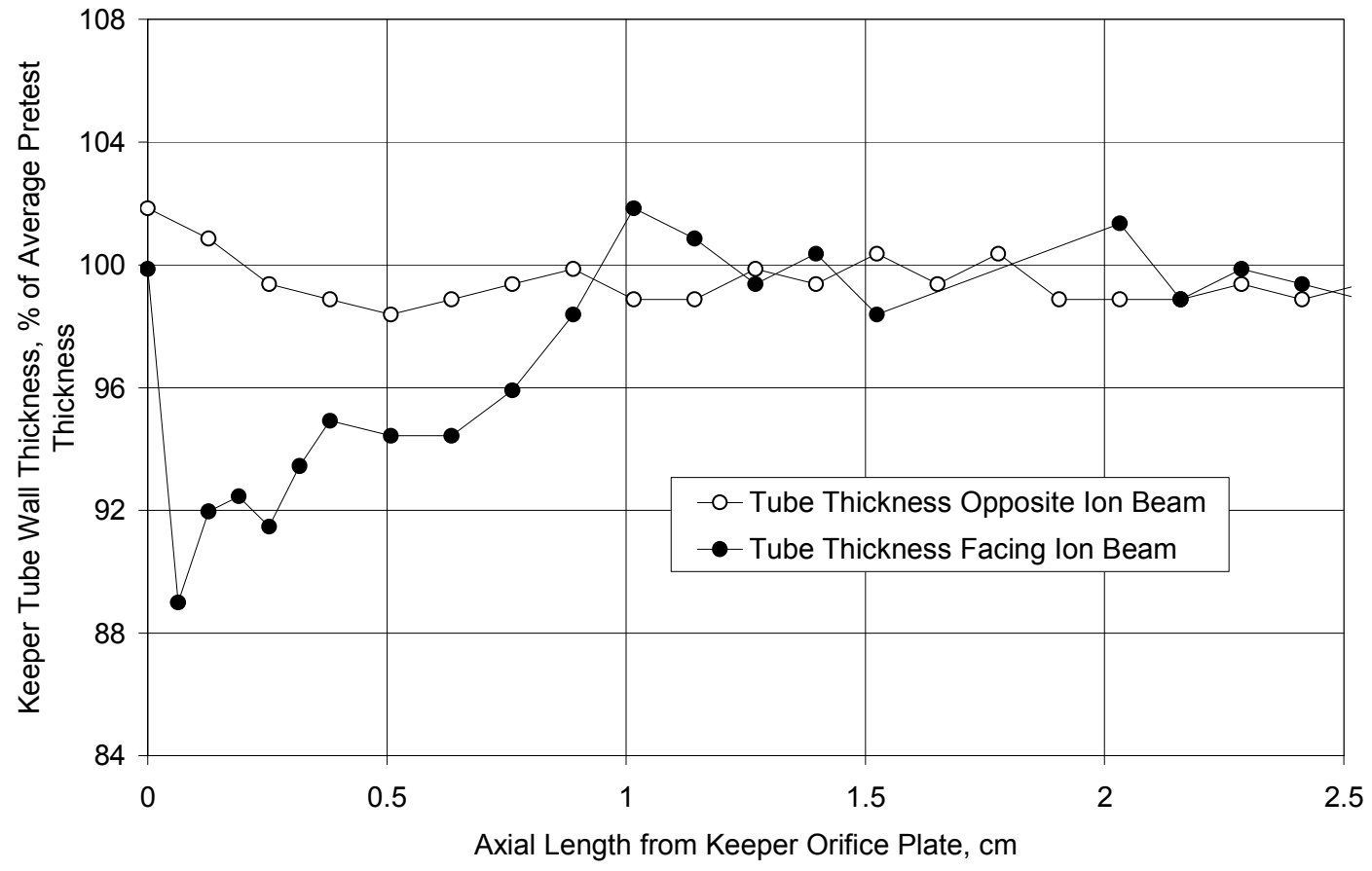

Figure 22. Post-test neutralizer keeper tube thickness as a function of axial location. Thicknesses facing and opposite the ion beam are included. 


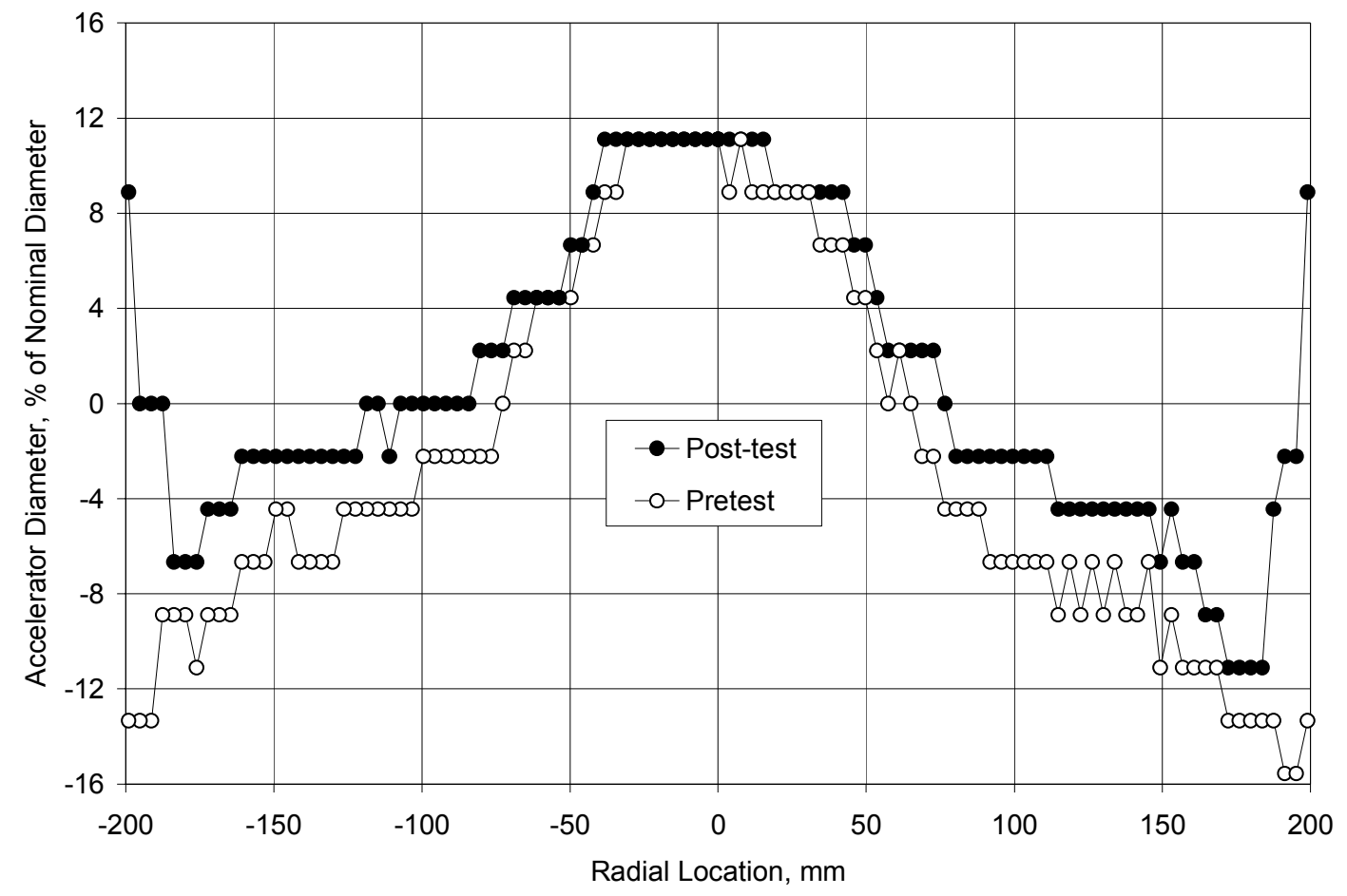

Figure 23. Pre- and post-test accelerator aperture diameters as a function of radius. Diameters were measured with pin gages that were in increments of $2.2 \%$ of the nominal accelerator aperture diameter.

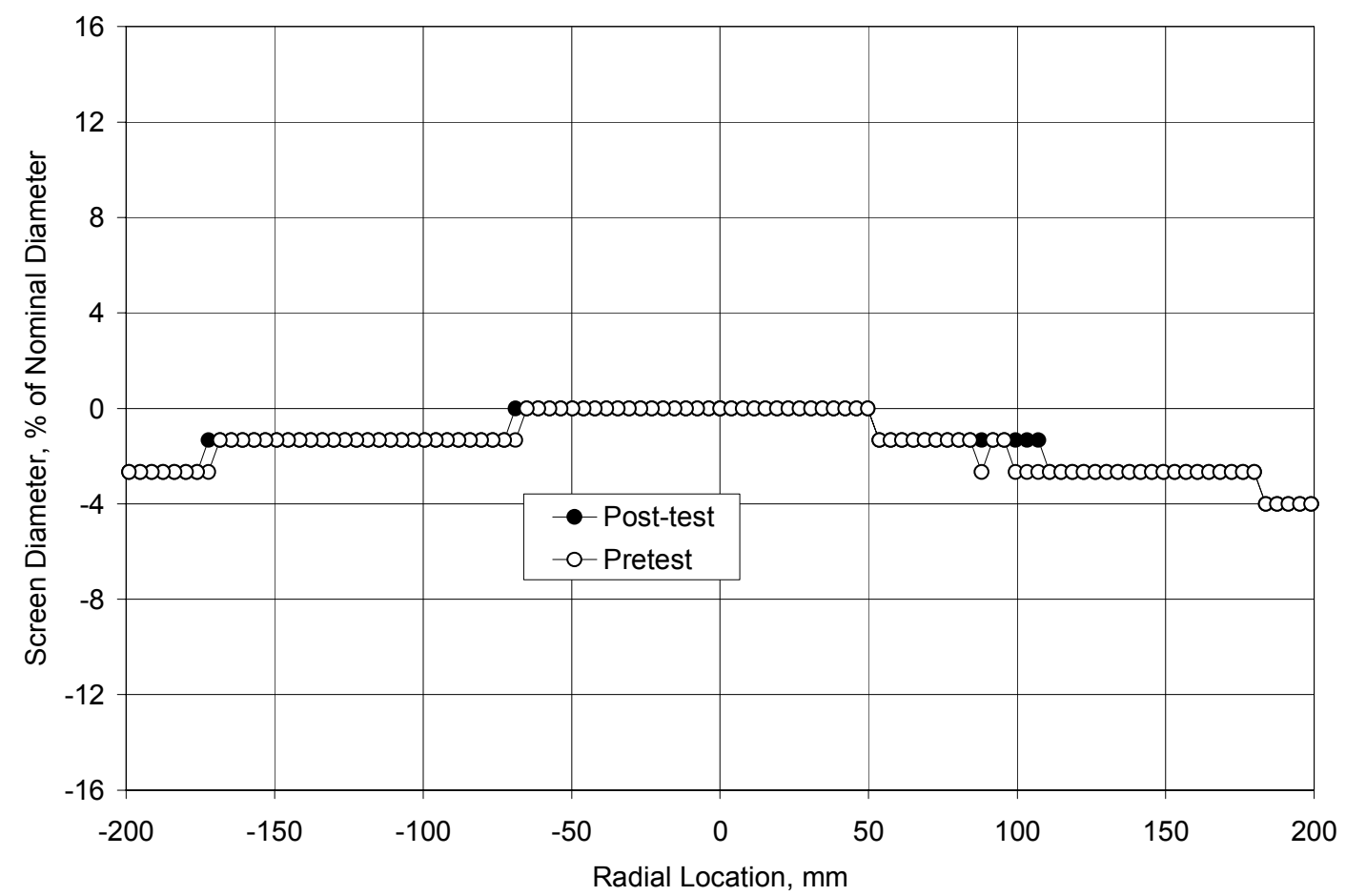

Figure 24. Pre- and post-test screen aperture diameters as a function of radius. Diameters were measured with pin gages that were in increments of $1.3 \%$ of the nominal screen aperture diameter. 

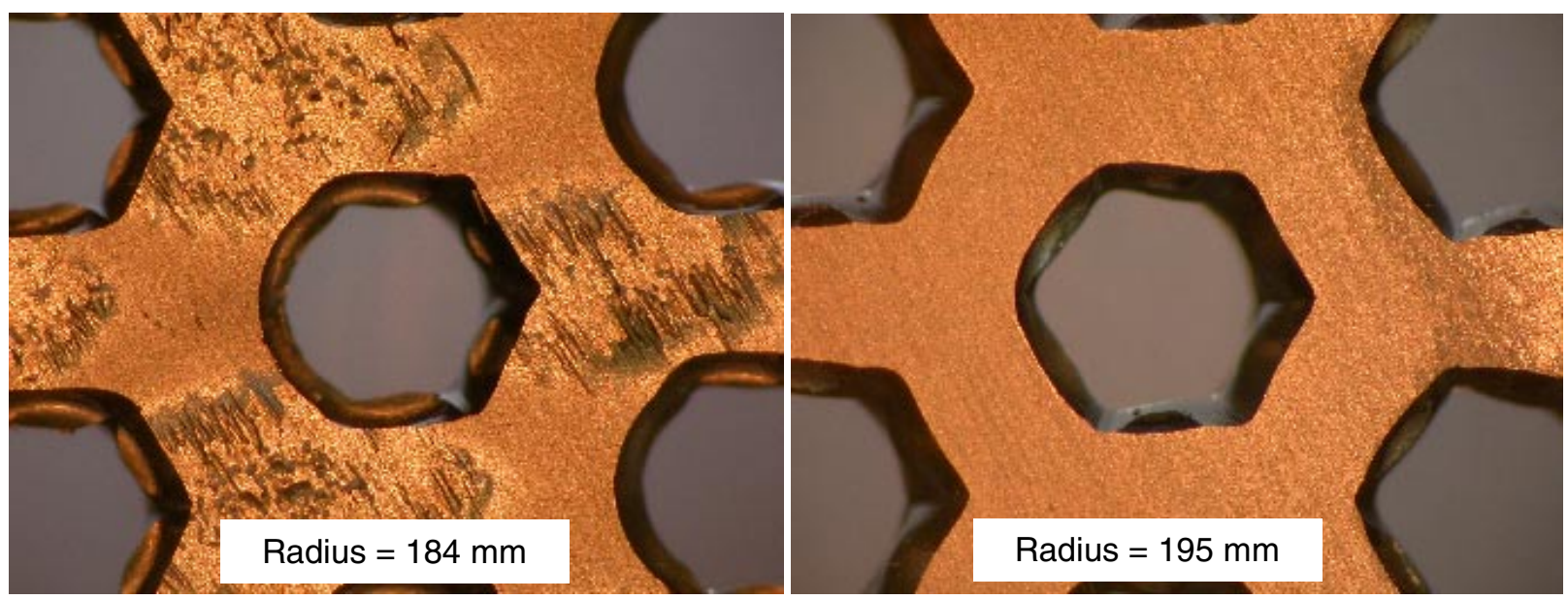

Figure 25. Post-test photomicrographs of downstream accelerator apertures at radial locations of 184 and $195 \mathrm{~mm}$.

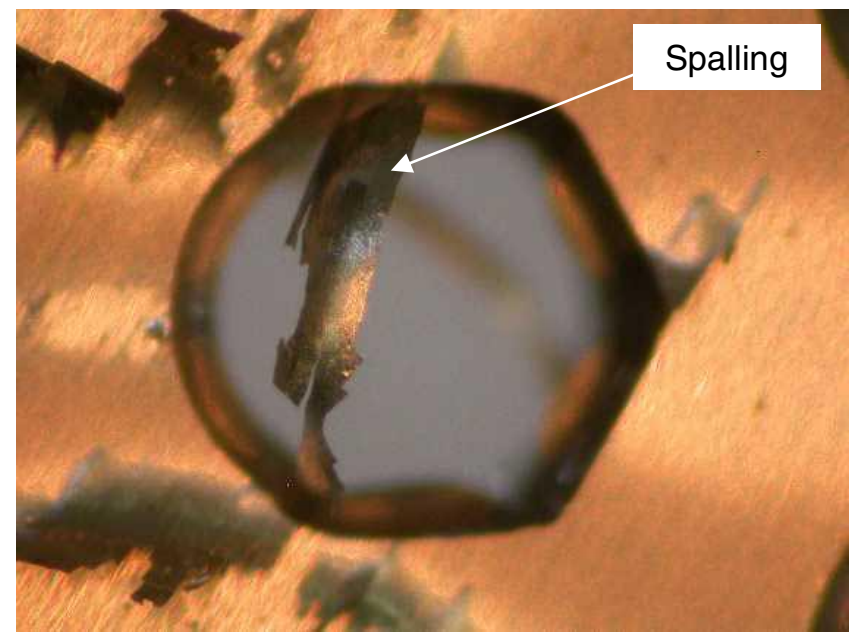

Figure 26. Post-test photomicrograph of a downstream accelerator aperture with spalling.

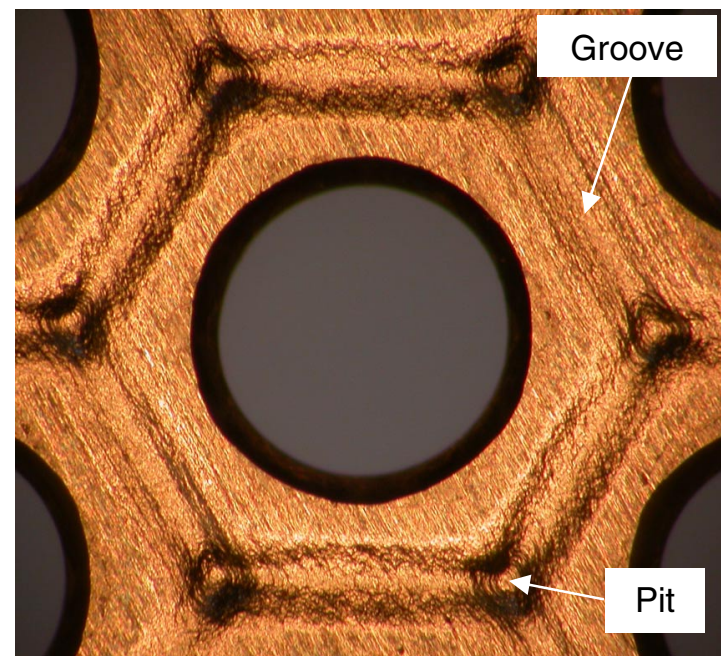

Figure 27. Post-test photomicrograph of the downstream center accelerator aperture with pit and groove erosion pattern. 


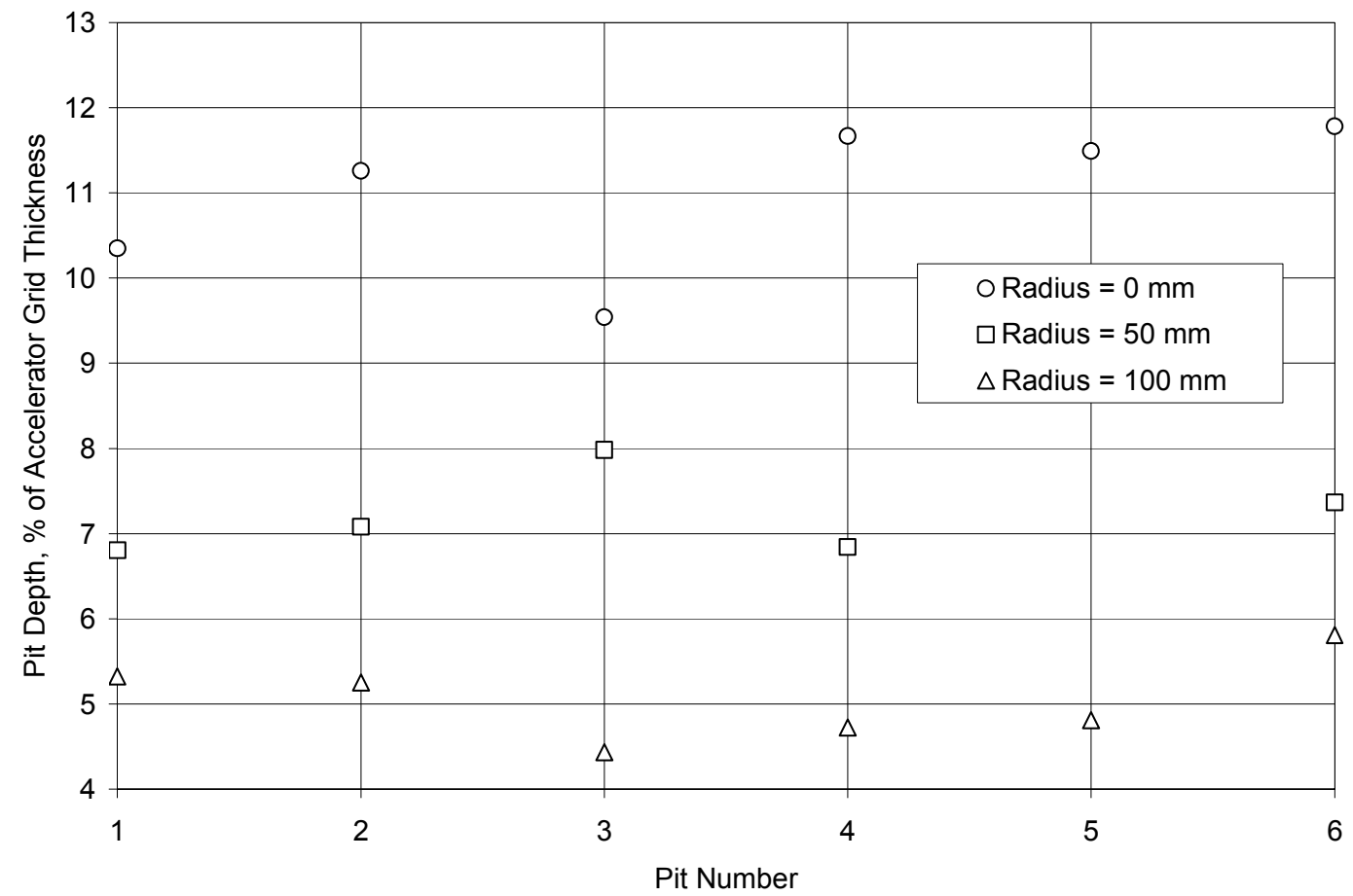

Figure 28. Post-test pit depths for the six pits surrounding the center, $1 / 4$-radius $(50 \mathrm{~mm})$, and mid-radius $(100 \mathrm{~mm})$ accelerator apertures.

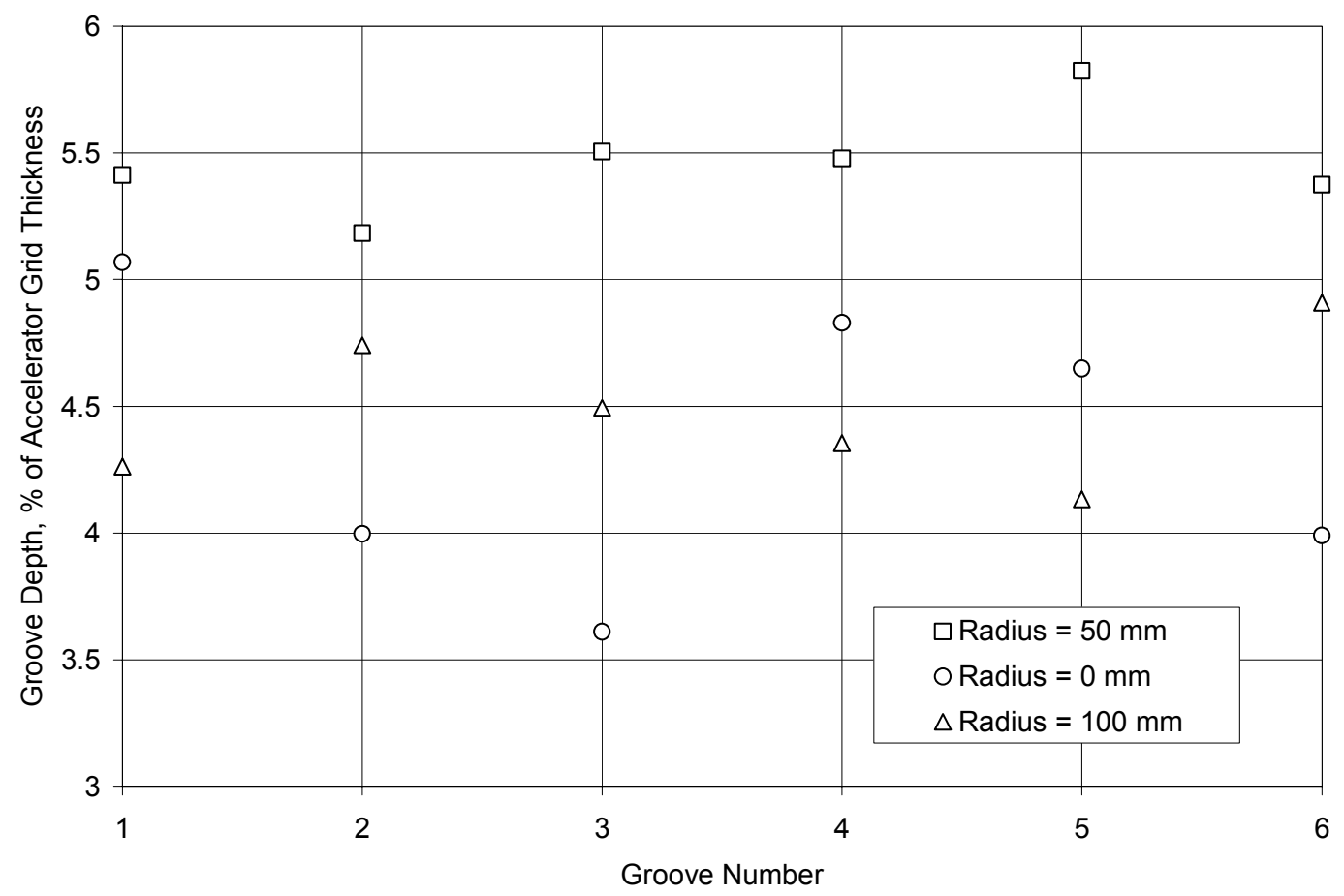

Figure 29. Post-test groove depths for the six pits surrounding the center, $1 / 4$-radius $(50 \mathrm{~mm})$, and mid-radius $(100 \mathrm{~mm})$ accelerator apertures. 


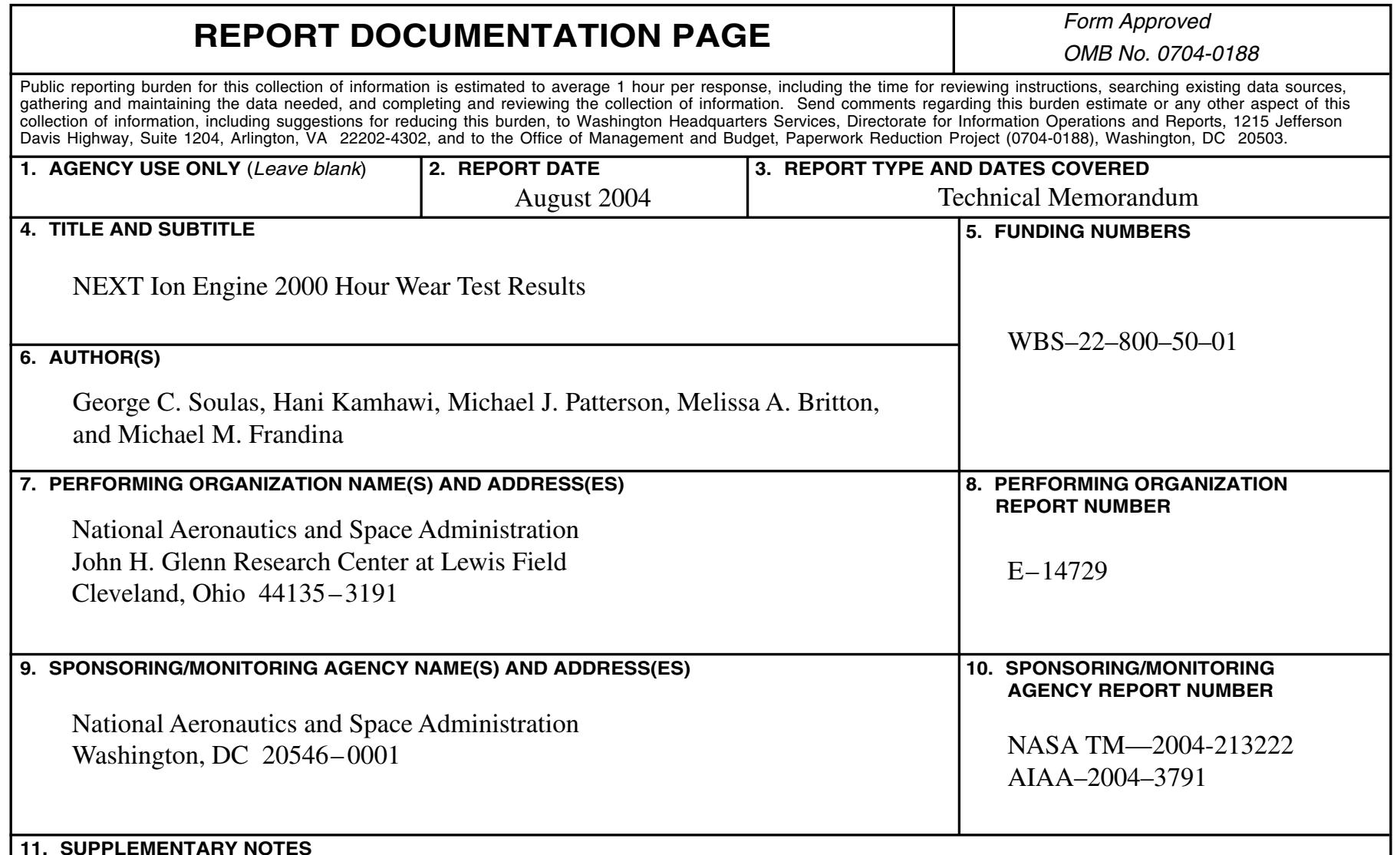

\section{SUPPLEMENTARY NOTES}

Prepared for the 40th Joint Propulsion Conference and Exhibit cosponsored by the AIAA, ASME, SAE, and ASEE, Fort Lauderdale, Florida, July 11-14, 2004. George C. Soulas, Hani Kamhawi, and Michael J. Patterson, NASA Glenn Research Center; and Melissa A. Britton and Michael M. Frandina, QSS Group, Inc., 21000 Brookpark Road, Cleveland, Ohio 44135. Responsible person, George C. Soulas, organization code 5430, 216-977-7419.

\begin{tabular}{l|l|l}
\hline 12a. & DISTRIBUTION/AVAILABILITY STATEMENT & \\
Unclassified - Unlimited & Distribution: Nonstandard & \\
Subject Category: 20 & \\
Available electronically at http://gltrs.grc.nasa.gov & \\
This publication is available from the NASA Center for AeroSpace Information, 301-621-0390. &
\end{tabular}

\section{ABSTRACT (Maximum 200 words)}

The results of the NEXT $2000 \mathrm{~h}$ wear test are presented. This test was conducted with a $40 \mathrm{~cm}$ engineering model ion engine, designated EM1, at a $3.52 \mathrm{~A}$ beam current and $1800 \mathrm{~V}$ beam power supply voltage. Performance tests, which were conducted over a throttling range of 1.1 to $6.9 \mathrm{~kW}$ throughout the wear test, demonstrated that EM1 satisfied all thruster performance requirements. The ion engine accumulated $2038 \mathrm{~h}$ of operation at a thruster input power of $6.9 \mathrm{~kW}$, processing $43 \mathrm{~kg}$ of xenon. Overall ion engine performance, which includes thrust, thruster input power, specific impulse, and thrust efficiency, was steady with no indications of performance degradation. The ion engine was also inspected following the test. This paper presents these findings.

\begin{tabular}{|c|c|c|c|}
\hline \multicolumn{3}{|l|}{ 14. SUBJECT TERMS } & $\begin{array}{c}\text { 15. NUMBER OF PAGES } \\
33\end{array}$ \\
\hline NSN 7540-01-280-5500 & & & $\begin{array}{l}\text { andard Form } 298 \text { (Rev. 2-89) } \\
\text { scribed by ANSI Std. Z39-18 } \\
-102\end{array}$ \\
\hline
\end{tabular}



